\title{
Wind Power Integration with Smart Grid and Storage System: Prospects and Limitations
}

\author{
Saad Bin Abul Kashem ${ }^{1}$ \\ Robotics and Advanced Computing \\ faculty \\ Qatar Armed Forces - Academic \\ Bridge Program, Qatar Foundation \\ Doha, Qatar
}

\author{
Azad Ashraf ${ }^{5}$ \\ Dept. of Chemical Engineering and Process Technology \\ College of North Atlantic \\ Qatar
}

\author{
Muhammad E. H. Chowdhury², \\ Amith Khandakar ${ }^{3}$ \\ Department of Electrical Engineering \\ Qatar University \\ Doha, Qatar
}

\author{
Jubaer Ahmed $^{4}$ \\ Faculty of Engineering, Computing \\ and Science \\ Swinburne University of Technology \\ Sarawak \\ Sarawak, Malaysia
}

\author{
Nushrat Shabrin ${ }^{6}$ \\ Business Faculty \\ University Malaysia Sarawak \\ Sarawak, Malaysia
}

\begin{abstract}
Wind power generation is playing a pivotal role in adopting renewable energy sources in many countries. Over the past decades, we have seen steady growth in wind power generation throughout the world. This article aims to summarize the operation, conversion and integration of the wind power with conventional grid and local microgrids so that it can be a onestop reference for early career researchers. The study is carried out primarily based on the horizontal axis wind turbine and the vertical axis wind turbine. Afterward, the types and methods of storing this electric power generated are discussed elaborately. On top of that, this paper summarizes the ways of connecting the wind farms with conventional grid and microgrid to portray a clear picture of existing technologies. Section-wise, the prospects and limitations are discussed and opportunities for future technologies are highlighted. It is envisaged that, this paper will help researchers and engineering professionals to grasp the fundamental concepts related to wind power generation concisely and effectively.
\end{abstract}

Keywords-Wind power system; wind turbines; energy storage system; microgrids; nation grids

\section{INTRODUCTION}

Wind energy has been widely used as a renewable resource to generate electricity in some countries such as the United States. This is because wind energy is relatively low cost and environmentally- friendly compared to other non- renewable energy resources such as coal, natural gas \&etc. Due to its advantages, many types of research had been carried out for further development of this energy source especially for the integration of wind energy with the smart grid. Hence, the aim of this research is an attempt to focus on the study of prospects and limitations of wind power integration with its power storage system and grid system. In this research, there is no simulation tool or experimental tool is used. This research is focusing on the peer review of the latest research papers that related to our topic. In Section 2 and 3, the use of vertical and horizontal axis wind turbines for a wind power system is reviewed. The energy storage system will be discussed in
Section 4. The integration of wind power with the microgrid and nation grid will be discussed in Sections 5 and 6, respectively.

\section{VERTICAL AXIS Wind TURBine (VAWT)}

The increment of renewable energy is very promising due to the rapid depletion of fossil fuels [1]. For the past decades, horizontal axis wind turbine (HAWT) has been widely used in commercials to generate electricity with higher capacity. However, a wind turbine with a vertical axis has been introduced to the world in the 1900s [2]. Vertical axis wind turbine (VAWT) has been first developed and studied in North America [3]. For instance, Cheng, et al. [3] said that the world's largest vertical axis wind turbine had been built in Canada in the year 1986. VAWT was proposed to encounter the problem of power losses of HAWT. It is the major drawback of HAWT. The use of gear mechanism on HAWT contribute a lot of power losses and high maintenance cost is needed for HAWT. All these factors lead to an increase in the total cost of HAWT. However, VAWT can overcome these problems by replacing the gear box to direct drive generator system which reduces power losses and maintenance costs [4]. Fig. 1 shows the VAWT commonly used in an urban area [8].

\section{A. Types of VAWT}

The design of VAWT is different from $\operatorname{HAWT}[1,3]$. VAWT is surrounded by its shaft along the vertical axis. The size of the VAWT is smaller than HAWT. The rotation of the turbine designed to be perpendicular to the wind direction to generate electricity. The generator and battery are connected at the bottom of the VAWT. Different type of rotor blade design determined the types of VAWT [5, 6]. Drag-type and lift-type are the most common types of VAWT around the world.

\section{B. Drag Type}

Drag type VAWT generates electricity by converting the torque created by the rotation of the wind turbine. A plurality of flat or concave cup-shaped blade is the most common design 
for drag type VAWT. From Fig. 2, normally the drag type devices consist of two or three scoops of the s-shape aerodynamic plate [7]. The blade would experience more drag when it is moving with the wind by less drag when it is against the wind direction. The spin occurs when there is differential drag created by the scoops on the VAWT. According to Wong, et al. [5], the most commonly used rotor for drag type is a Savonius rotor and Sistan rotor. It uses the blades as the obstacle to the wind which utilizes the force to rotate the wind turbine. Nevertheless, it has the better self- start ability compare to lift type VAWT but lower power coefficient on the system [5].

\section{Lift Type}

Lift type VAWT has better efficiency compared to drag type. The blade of lift type VAWT is designed to aerofoilshaped blades. The blades rotate by the aerodynamic lift forces that created when the air passes through the wind turbines. There is always positive static torque that can be observed in helical blades regardless of the incident angles shown in Fig. 3. Toja-Silva, et al. [8] had proved that the helical Savonius wind turbine has a higher power coefficient compare to traditional Sanonius rotor wind turbine. However, it lacks a 'self-initiate' force compare to drag type VAWT [5, 7]. Therefore, a hybrid combination of both drag and lift type of wind turbine are proposed to encounter the weaknesses [5, 8, 9].

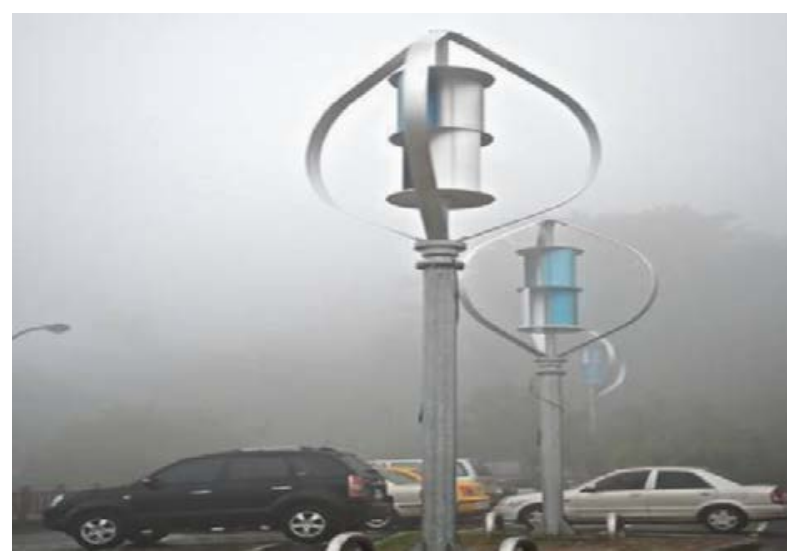

Fig 1. Hybrid VAWT.

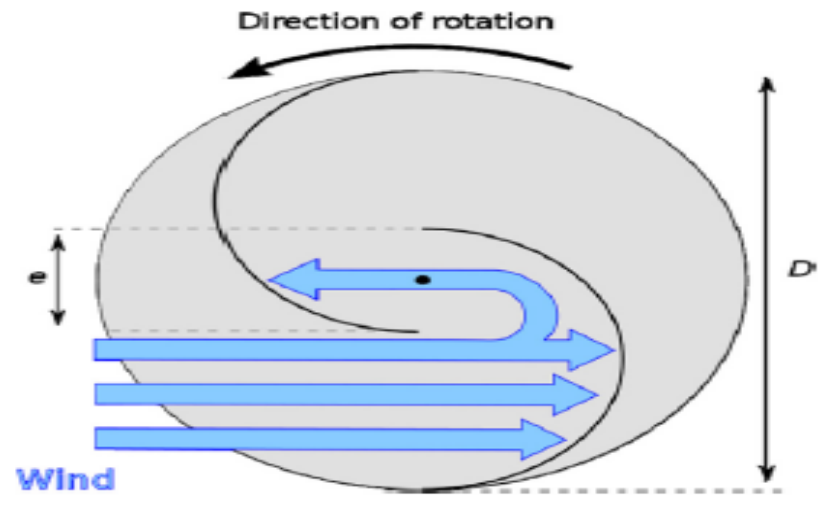

Fig 2. Working Mechanism of Drag-Type VAWT.

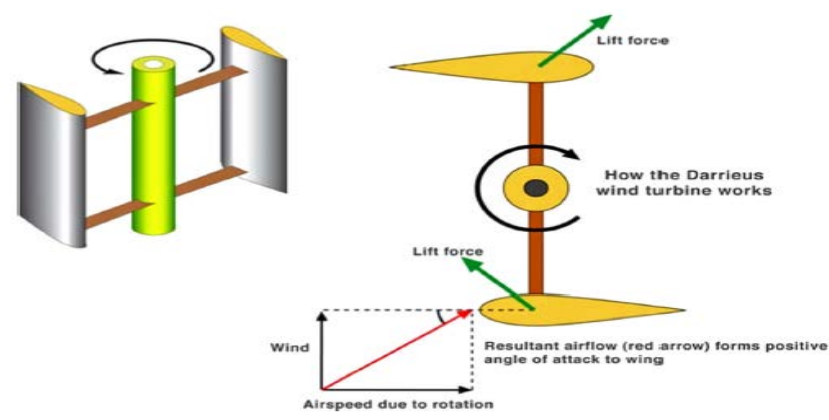

Fig 3. Working Mechanism of Lift-Type VAWT.

\section{Working Mechanism}

According to Shahariar et al., [10], the blade on the VAWT is designed to be symmetrical and the angle of the blade is set corresponding to the turbine. By doing this, VAWT can capture the wind in all directions. Fig. 4 shows the various components of the VAWT [10]. First of all, the rotor in VAWT is used to convert the wind energy into mechanical. The rotor will be installed in the hub. The hub is connected to all the rotor blades due to the magnetic levitation. The hub is suspended on the magnets to increase the efficiency of the output. The most common material for the hub is cast iron and cast steel [10]. Besides, the shaft below the hub gets turned by the rotation of rotor blades. Then the generator below the shaft converts the mechanical energy into electrical energy.

1) Magnetic levitation: To maximize the rotor efficiency, magnetic levitation was proposed in the design of VAWT [1]. The aims of proposing magnetic levitation are to nullify the weight of the rotor in the system. Levitation magnetic system is done by installing two sets of magnetized ring magnets in such a way that repelling with each other. For instance, there is a magnet that will be installed at the shaft and another magnet under the supporting hub. With this, the repulsion of the magnet can partially nullify the hub and other rotating parts. Therefore, it can reduce the friction between the rotor and mechanical parts in the hub.

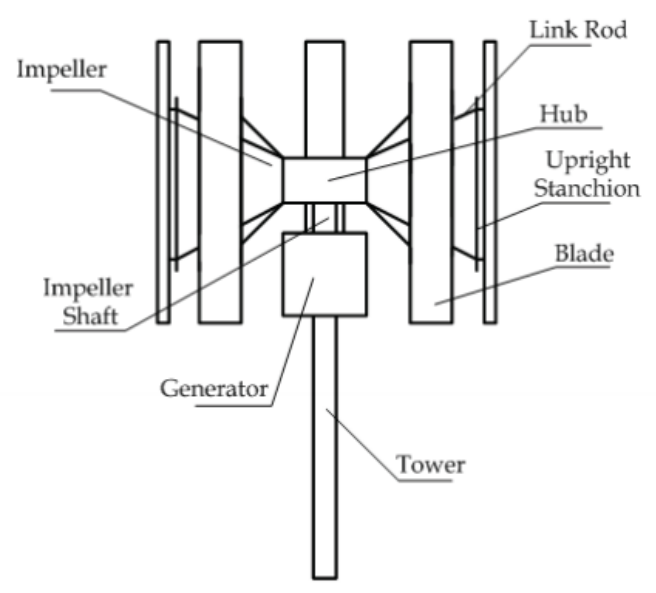

Fig 4. Various Component of the Typical VAWT. 
2) The airfoil of the Turbine: According to Jin, et al. [7], lift-type VAWT will gradually become the representative of the VAWT because it has a higher efficiency compared to drag-type VAWT. The design of aero-foil is essential to improve the Darrieus type turbine [1]. Nevertheless, the shape and thickness of the aerofoil are determined by the specific data. The National Advisory Committee for Aeronautics (NACA) and Sandia National Laboratory had co-operated to come out with most of the review and data for the different types of aerodynamic characteristics for aerofoil. For instance, the lift and drag coefficient of different type of aerofoil with Raynolds number and ranging angle between 0 to $180^{\circ}$ are provided by NACA.

\section{E. The Solidity of the Turbine}

The number of blades is depending on the smoothness of the rotor operation [11]. However, the number of blades corelated with the solidity. The solidity of the turbine is defined by the ratio of the total swap area and the radius of the turbine. The number of blades and length of the chord is influencing the total area. Nevertheless, all these parameters are affecting the efficiency of the self-starting of the wind turbine. Solidity $(\sigma)$ can be computed by using (1) [11].

$\sigma=\frac{N_{c}}{R}$

Where $\mathrm{N}$ is the number of blades, $\mathrm{C}$ is the length of the chord (m) and R is the radius of the rotor (m). Nonetheless, the number of blades is also affecting the power coefficient of the wind turbine.

\section{F. Power Coefficient}

Furthermore, the Betz limit is an essential and powerful performance indicator for VAWT [10]. The upstream and downstream stream wind for VAWT is different. Therefore, it is important to study the available wind kinetic energy can be extracted from a wind generator. Furthermore, the theoretical maximum rotor power coefficient, that achieved by the past research is 0.59. However, Shahariar and Hasan [10] had proved that the two blades VAWT has the 0.46 of practical limit for under high wind and the three-blade VAWT has 0.50 of Nevertheless, the drag-type VAWT only can operate at $1 / 3$ of the Betz limit [12]. There are (2) and (3) used to determine the power co-efficient or efficiency of the rotor [1].

$C_{P}=\frac{\text { captured mechanical power by blade }}{\text { Available power in the wind }}$

$C_{P}=\frac{T_{\omega}}{0.5 \rho A V^{2}}$

\section{G. Efficiency of VAWT}

According to Shahariar et al., [10] and Zhuga et al., [13], the wind turbine efficiency can be computed by using (4).

$P_{t}=0.5 \rho A V^{3}$

The power produced by the generator and the amount of wind energy that can be captured can be determined by the (5).

$P_{a}=T \omega$

Whereas the torque, $\mathrm{T}$ can be determined by (6).
$T=0.5 \rho A C_{t} V^{3}$

The angular velocity or RPM of the VAWT $\omega$ can be computed by (7).

$\omega=\frac{\lambda V}{R}$

According to Ragheb [14], aerodynamic turbine (lift-type) has a higher efficiency compared to impulse devices (dragtype). For instance, lift-type has an efficiency of approximately 60percent whereas the drag-type only $19-40$ percent. This is because there is the possibility of the zero wind speed behind the turbine which clogging any flow through the rotor.

Power efficiency and rotor efficiency of VAWT are determined by the blades design and the rotor design $[1,15$, 16]. The aerofoil shape design is essential for the blade to promote or ensure the efficiency of the wind turbine [15, 17]. Besides, the number of blades also affects the smoothness of the rotor operation of the wind turbine. Cheng, et al. [3] had performed the changes in wind turbine efficiency by using a different number of blades. The number of blades is the main factor that affects the aerodynamic load on the wind turbine which includes thrust and side force. According to the researcher Cheng, et al. [3], increasing the blades can reduce the fatigue and bending moment of the wind turbine. Nevertheless, three to four blades are reaching the limitation of additional effect [18].

Furthermore, flexible blades are proposed to increase the efficiency of VAWT [7, 8]. The main intention of proposing the flexible blade is to reduce the vibrations transmitted to the VAWT. Nevertheless, the deflector sheet on the VAWT can increase the efficiency of the system as well [8]. Cheng, et al. [18] had proved that the deflector sheet on VAWT shows the higher power coefficient compares to the rotor with two blades.

\section{H. Advantages of VAWT}

VAWT is workable under omnidirectional flow [14]. It can catch the wind in all directions. Therefore, VAWT does not require a yaw mechanism for operation [5, 15, 19]. It can sustain under much harsher environment namely higher wind turbulent condition compare to HAWT due to its omnidirectional characteristic. According to Ragheb [14], HAWT does not need to be shut down and it can sustain up to $50 \mathrm{~m} / \mathrm{s}$.

Besides, Wong, et al. [5] claims that the blade of VAWT can be easily manufactured compare to HAWT. The uniform section and untwisted characteristic of blades make them easy to fabricate. For instance, the blade of the VAWT does not require twisting or tapering to optimize the performance.

Furthermore, VAWT does not require to be built as high as HAWT. The size of the VAWT is much smaller than HAWT. According to Ragheb [14], a small VAWT only require $10 \mathrm{~m}$ height to capture the wind. Therefore, they are less visible and can be widely used in the urban area.

Apart from that, there is lower rotational speed can be observed on the VAWT [8]. Therefore, the noise contributed by VAWT is lower than HAWT. The lower rotational speed also results in lower vibrations transmitted to the structure. 
Besides, VAWT does not require a yaw-control mechanism. With this, the lower maintenance is required for VAWT thus lower cost is needed for VAWT.

\section{HORIZONTALAXIS WIND TURBINE (HAWT)}

Horizontal axis wind turbine (HAWT) was one of the most common types of wind turbines used for generating wind power [20]. It was being used in both large and small scale. Large-scale utilization of HAWT was usually adopted in wind farms or offshore areas; while small-scale usage of HAWT usually occurred within the residential area, normally integrated with solar panel system [21, 22]. The rotor blades of this particular type of wind turbines are rotating about the horizontal axis in a vertical plane[23]. The main components of horizontal axis wind turbines were the rotor blades, gear-box, electrical generators and the tower-like supporting structure. One of the distinct advantages of HAWT was that it was equipped with a tower, which was able to expose the wind turbine to higher wind speed at an elevated height [23, 24]. Fig. 5 and 6 show the typical 3 blade HAWT and components of horizontal axis wind turbine respectively [21, 35].

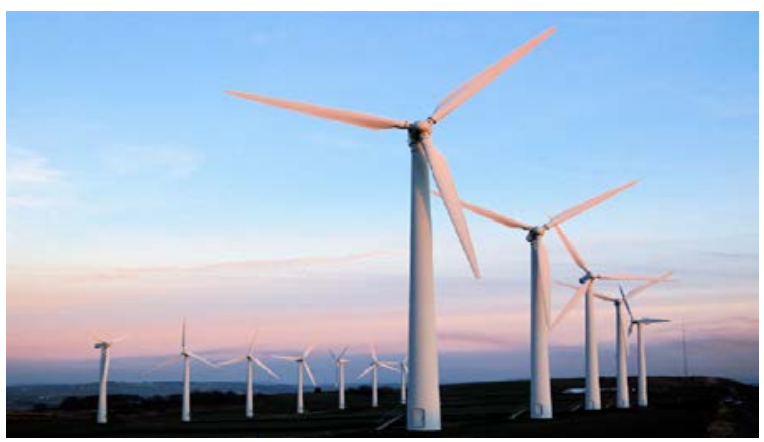

Fig 5. Typical 3 Blade Horizontal Axis Wind Turbine.

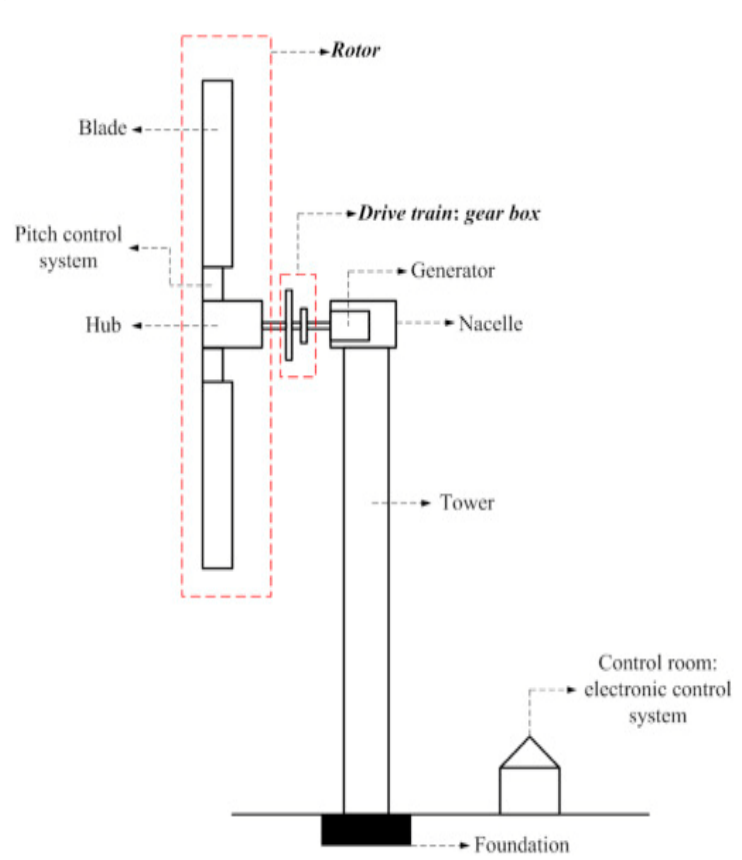

Fig 6. Components of Horizontal Axis Wind Turbine.

\section{A. Working Mechanism of HAWT}

HAWT had to face the wind direction for it to work with the maximum efficiency. It uses the aerodynamics force of lift to convert the wind energy into electrical power [25]. Most of the rotor blades of HAWT was designed to be airfoil shape. Fig. 7 shows the typical airfoil-shaped blades for HAWT [26].

When the wind blows through the airfoil-shaped rotor blades with the configuration in Fig. 7, the wind velocity that passes through the upper part of the blades would be faster compared to the wind velocity at the bottom of the blade [26]. As higher velocity would result in lower pressure, a pressure difference would occur between the upper and lower zone of the blades. This pressure difference would create a lift force to initiate the movement of the blades in rotational motion and cause the driveshaft to spin. Although the outer blades were rotating at a high speed, the driving shaft was not spinning as fast as the rotor blades. For most of the HAWT, a gearbox was installed within it to convert the low rotational speed of the drive shaft into a higher rotational speed [27]. This was to ensure that the rotation speed was fast enough for the electrical generator to generate power.

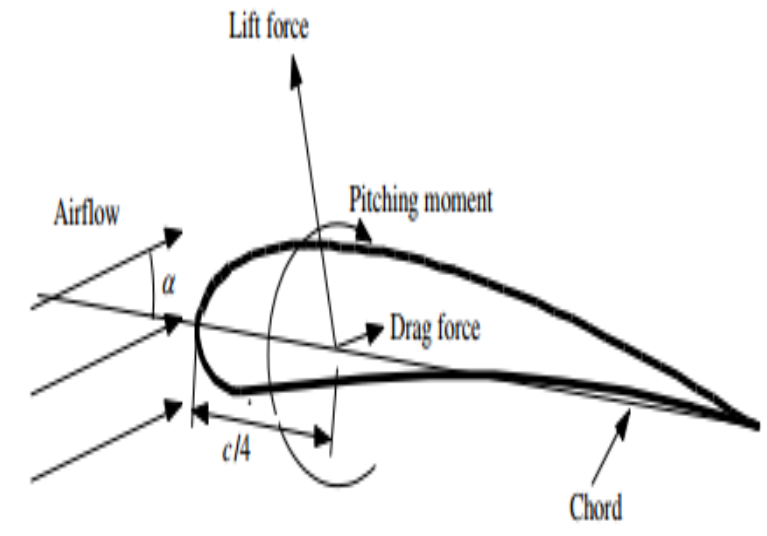

Fig 7. Airfoil-Shaped Rotor Blades for HAWT.

\section{B. Power Generation is HAWT}

The power that generated in HAWT can be computed through the equation:

$P=\frac{1}{2} C_{p} \rho A v^{3}$

Where, $\mathrm{Cp}=$ Power Coefficient

$\rho=$ density of air

$\mathrm{A}=$ area by the wind blades

$\mathrm{v}=$ wind speed

\section{Factors Influencing Power Generation in HAWT}

A few factors affect the power generation in HAWT. These factors include the wind speed, power coefficient and the area swept by the rotor blades of HAWT.

1) Wind Speed: The power generation in the HAWT is strongly influenced by wind speed. The wind speed was classified into three different types, namely cut-in wind speed, 
rated output wind speed and cut-out wind speed. The cut-in wind speed referred to the minimal wind speed required for the power generation to initiate $[28,29]$. As mentioned in the equation, the power produced was governed by the wind speed, thus a lower wind speed results in a lower power being produced. As the rotor blades continued to rotate, a continuous increment in the wind speed would occur until it reaches rated output wind speed. At the rated output wind speed, the maximum output power could be produced by the electrical generator [30]. In cases where the wind speed went beyond the rated output wind speed, there was no increment in the power output because it was beyond the limit of the electrical generator. As the wind speed kept on increasing, a cut-out wind speed would be reached and the rotating of the rotor blade would be forced to stop to prevent overloading of the wind turbine [31]. Thus, normally in HAWT, the powerregulating system is required as it is often exposed to high wind speed [21, 23, 29]. One of the common power regulating system adopted in HAWT was the pitch angle control system [31]. Whenever the wind speed exceeded the rated wind speed value, the pitch controller would increase the pitch angle to reduce the rotation of the wind turbine [31].

2) Power Coefficient, $C_{p}$ : The output power is always lower than the actual power within the wind due to the energy lost during the conversion of wind energy into mechanical power. This conversion efficiency was known as Power Coefficient, $\mathrm{C}_{\mathrm{p}}[32,33]$.

$C_{p}=\frac{\text { output power }}{\text { wind power }}$

The theoretical maximum value of the power coefficient was found to be 0.593, known as the Betz limit [34, 35]. However, the practical power coefficient was not able to reach 0.593 due to different configurations of a wind turbine which leads to inefficiencies and losses of energy[36]. According to Sedaghat and Mirhosseini [35], modern HAWT worked with a power coefficient of 0.5 , which is very close to the Betz limit. The power coefficient was closely related to the tip speed ratio. Tip speed ratio, $\lambda$ was the ratio between the speed at the tip of the blade and the wind speed.

$\lambda=\frac{\text { Speed at the rotor tip }}{\text { Wind Speed }}$

An optimum tip speed ratio was required for maximizing the efficiency of the conversion [36]. Aside from that, HAWT utilized the lift force instead of drag force for rotating the blades hence the conversion of energy was more efficient [25]. This would result in a higher power coefficient.

3) Swept Area: The swept area of the wind blades had a significant impact on the power generated. The swept area referred to the areas being swept by the blades when rotating Fig. 8 shows a detailed view of the swept area by HAWT [25].

The equation used to calculate the swept area of HAWT was the same as calculating the area of a circle.

Swept Area, $S=\pi\left(\frac{d}{2}\right)^{2}$ where the $\mathrm{d}$ value referred to the rotor diameter [37]. An increment in the rotor blades length would increase the swept area of the wind turbine. HAWT normally had a large swept area, therefore the installation of the HAWT had to take account of the area swept when operating.

\section{Yaw Mechanism for HAWT}

As wind direction often changes, HAWT was required to install the yaw system [20]. The yaw system was able to control the rotor blades and ensure that it faced the wind direction whenever the wind direction changes [38]. However, one of the limitations of this yaw control system was that when the wind turbine was subjected to a sudden change in wind direction, it would result in the wind turbine to run with yaw errors. Yaw error was a term used to describe the situation where the wind direction was not perpendicular to the rotor blades; normally occurred when the turbine was changing its direction [20]. When the yaw error occurred, the power generated would drop significantly.

\section{E. Other Considerations}

1) Noise: HAWT usually causes a lot of noise when the rotor blades were spinning. This was because the blades of HAWT was usually exposed to higher wind speed as it was installed at the top of the tower [25]. Apart from that, HAWT usually operates at a higher tip speed ratio, result in creating a lot of noise from the wind turbine [20,36].

2) Cost: The cost analysis of HAWT had to take into consideration a few different aspects. As HAWT had been widely used in the past decades, cheaper solutions in manufacturing HAWT had been developed in these years[20]. Despite having cheaper manufacturing costs, the installation and maintenance cost of the HAWT was expensive. This was because most of the parts of HAWT was located at the higher part of the tower which complicates the installation and the maintenance process [20].

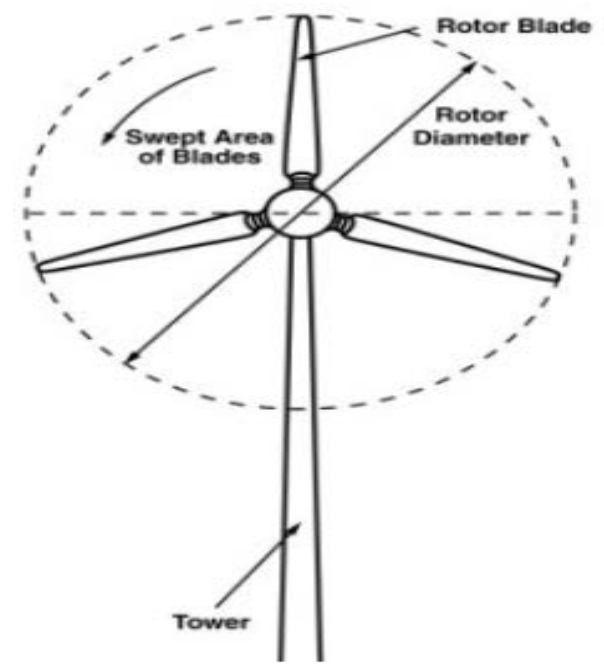

Fig 8. Area Swept by Horizontal Axis Wind Turbine. 


\section{Wind ENERgy STORAge System}

\section{A. Energy Conversion in Wind Energy System}

The generation part of a wind energy system is done by a wind turbine which comes in different sizes and a different number of blades. The kinetic energy in the flowing wind has been converted into mechanical energy by the turbine to spin the generator for the generation of electricity. The generated electrical power will either be in the form of Alternating Current (AC) or Direct Current (DC) depends on the design of the wind turbine. Electrical cables will be used to transmit the generated electricity to other electrical components in the system for different applications. If the output of the wind generator is DC, a charge controller or voltage regulator will be used to convert the DC to a suitable range of voltage level according to the DC appliances, to charge the batteries, or to be injected into the local DC microgrids. Besides, DC can also be transformed into AC with a voltage level of $240 \mathrm{~V}$ (singlephase) or $415 \mathrm{~V}$ (three-phase) and frequency of $50 \mathrm{~Hz}$ by an inverter. The AC will be used to supply the local AC appliances or its voltage will be stepped up further by the power transformer for transmission purposes to reduce the power loss [39]. The AC can be injected into either the local microgrids or the national grids to supply the power demand in other areas. If the generated power by the generator is already in AC, the inverter will not be required for the system but a rectifier will be needed to convert the AC into DC so that it can be stored in the battery bank of the system. A sample diagram of the flow of a wind energy system has been shown in Fig. 9 [40].

\section{B. Rectifier}

If a wind turbine's generator uses an alternator, the output of it will be in three-phase AC. A three-phase rectifier is needed to convert the $\mathrm{AC}$ output from the generator into $\mathrm{DC}$ before connecting to the voltage regulating device to charge the battery bank [41]. A rectifier is a Power Electronics Device (PED) which comprises several diodes/thyristors. However, the output of a rectifier is always not plain DC but pulsating DC which will be regulated before it has been used to charge the battery bank. The battery bank will provide a smooth and continuous DC output for the circuit in the DC appliances to work properly. Fig. 10 shows the schematic diagram of a gridtied wind-mill system with the application of a rectifier [42].

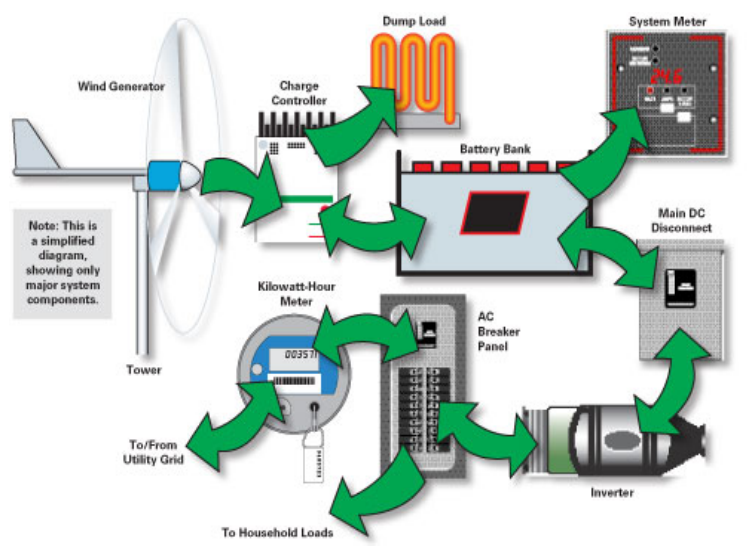

Fig 9. Grid-Tied Wind Energy System with Battery Storage.

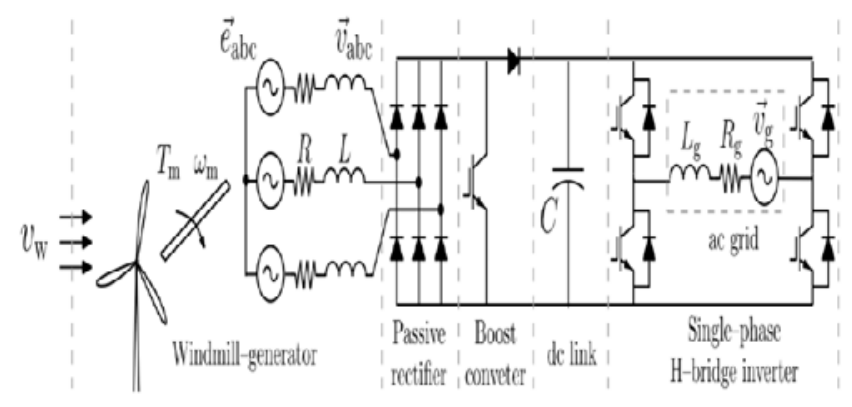

Fig 10. The Application of Rectifier in Wind Energy System.

\section{Regulator and Charge Controller}

A charge controller or a regulator is the device that limits and controls the amount of current that will be used to charge the battery bank. Unlike solar charge controller which will disconnect the connection between the source (solar panels) and charge controller itself when the battery is fully charged, a wind turbine charge controller needs to monitor the battery voltage constantly and able to turn on a dump load (also known as a shunt) if that voltage approaches the float charging voltage of the battery instead of shorting the output of the wind generator as shown in Fig. 9. A dump load, in this case, could a supplementary water heater or underfloor heating device instead of a braking resistor to optimize the generated energy. While a wind generator is rotating at high speed, sudden disconnection of the load will create a huge current spike that might destroy the charge controller and leads to over-speeding of the turbine in which will damage itself. There are two major types of charge controller technologies that can be found on the market where they are Pulse Width Modulation (PWM) and Maximum Point Power Tracking (MPPT). Fig. 11 is showing an example of the implementation of an MPPT charge controller in a wind energy system [43].

\section{Grid Tie Inverter and Transformer}

An inverter is a device that injects electrical power generated by any distributed power generation source in a stand-alone system, micro-grid or the nation grid [44]. When the output from the wind generator is in DC, a power inverter will be needed to convert it to AC before it has been supplied to any AC appliances or injected into the grid. A Step-up transformer will be needed to boost the voltage level which can reduce power loss during the transmission of electricity through the grid. The transformer is normally located at the base of the wind turbine. However, grounding transformer will be located at the critical points through the wind farm which provides a neutral point where all the electricity is then interconnected with a major collector step-up transformer that is connected to the grid.

\section{E. Energy Storage System}

As mentioned above, an energy storage system will be used to store the excess energy that is generated by the system to be used when the energy demand exceeds the output power of the wind energy system. The electrical energy generated from a wind turbine can be stored in different forms of energy. 


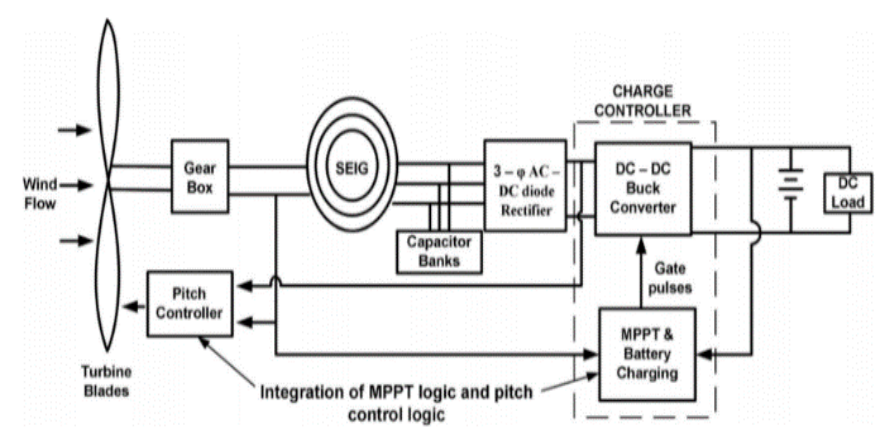

Fig 11. Integration of MPPT Charge Controller with Wind Energy System.

1) Lead Acid Battery: There are two major lead-acid batteries that can be found in the current market where they are Flooded Lead Acid (FLA) and Valve Regulated Lead Acid (VRLA). FLA batteries are built from two lead plates which are immersed in the electrolyte which is sulphuric acid in this case. Meanwhile, VRLA batteries operate in the same way while having an extra sealed pressure-regulating valve that works to prevent the hydrogen from venting and release the air in the battery cell [45]. VRLA batteries are having a higher price and lower life-cycle compared to FLA batteries but it comes in smaller size and weight while being maintenancefree. Lead-acid battery often being considered as a support of the wind power system compared to other types of the battery due to its small power density, lower depth of discharge and the shorter number of its life cycle.

2) Nickel Cadmium Battery: Nickel Cadmium battery is using nickel hydroxide and metallic cadmium as its electrode while both electrodes are separated by nylon divider and having aqueous potassium hydroxide as the electrolyte for the battery. Nickel Cadmium Battery can operate at a wider temperature range compared to a lead-acid battery. It also offers excellent cycle life and exceptional tolerance of high discharge rates. However, the toxicity of Cadmium and direct competition from other batteries like Lithium-ion leads to its decreased popularity since the 1990s [46]. It has also been banned by some European countries due to environmental issues.

3) Lithium-Ion Battery: Lithium-Ion battery is using litigated metal oxide as its cathode and graphite carbon with layer structure as its anode [47]. It is widely used in consumer electronics, automotive and energy storage systems especially for large scale applications like wind farm storage. LithiumIon battery comes in small weight, high cell voltage, high overall cell efficiency and power density. Lithium-Ion batteries are also having long life deep cycles which means significantly more to deep discharging. It is also one of the cleanest battery technology that can be found on the market that is having up 0.1 small self-discharge per month [45]. However, a lithium-ion battery with all these features and high-quality performance as shown in Fig. 12 also comes with an extremely high initial cost compared to other types of battery like lead-acid and Nickel Cadmium [47].

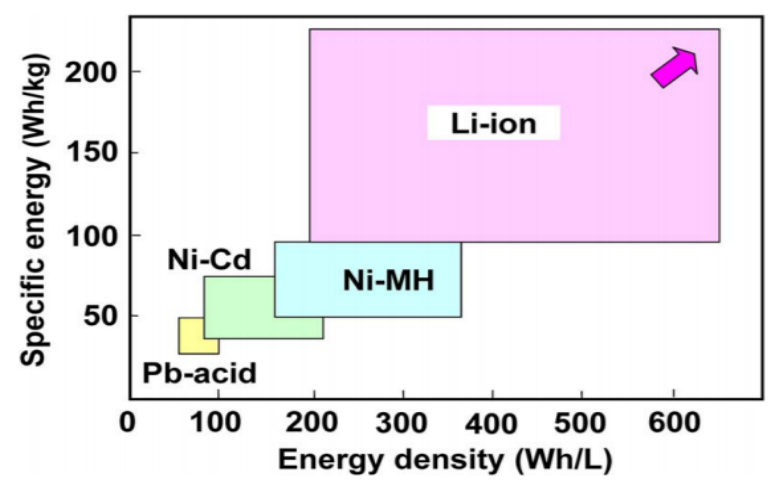

Fig 12. Comparison of Batteries.

4) Sodium Sulphur Battery: Sodium Sulphur battery is a kind of high-temperature battery that is usually constructed in a tall cylindrical configuration. The anode and cathode of the battery are made by molten Sulphur and molten sodium respectively while the electrolyte, in this case, is normally $\beta$ alumina. A diesel Genset is often installed along with a system that is using Sodium Sulphur batteries because the batteries will suffer some serious damage if it is cooled down without being fully charged. The Sodium Sulphur battery can become a serious player in large- scale energy storage application dues to its high energy density and deep cycles in comparison to the Lead-Acid battery. The initial cost for Sodium Sulphur battery is relatively high for now because it is a new battery technology where there is only one manufacturer is producing it, NGK Insulators (Japan) [45]. However, the price is considered to drop with a mass production since the materials of the battery are inexpensive, abundant and recyclable. A schematic diagram of a central sodium electrode tubular Sodium Sulphur cell has been shown in Fig. 13 and Fig. 14 shows the discharge reaction scheme of Sodium Nickel Chloride Battery [48].

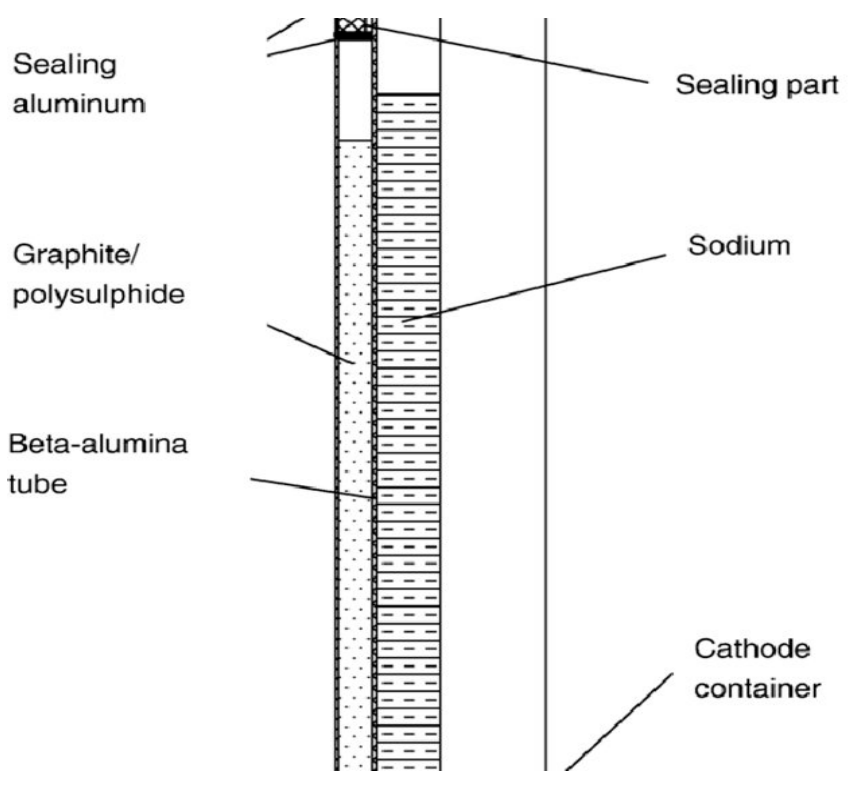

Fig 13. The Discharge Reaction Scheme of Sodium Nickel Chloride Battery. 


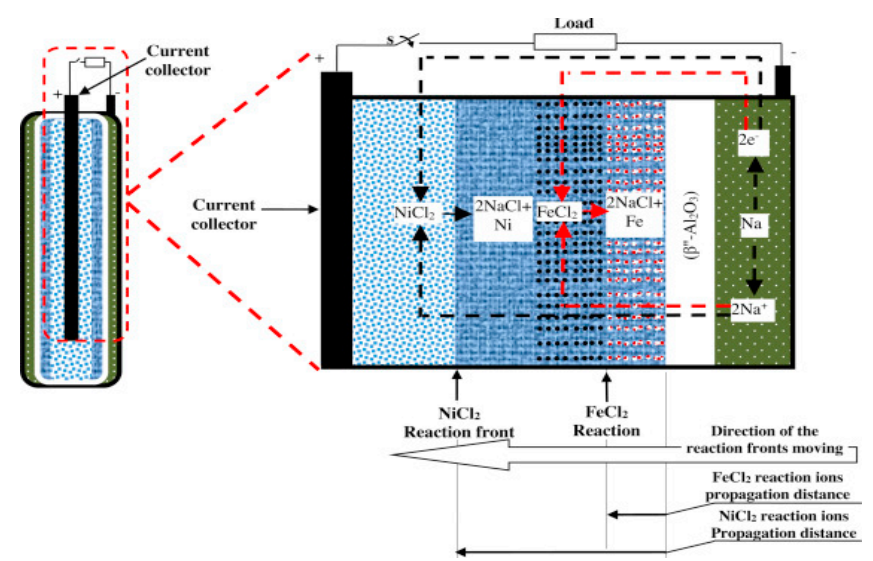

Fig 14. The Discharge Reaction Scheme of Sodium Nickel Chloride Battery.

5) Flow Battery: Flow Battery provides a well-balanced solution for a large-scale energy storage system for renewable energy due to its flexible modular design and the ability to store a large amount of energy up to Megawatts (MW) [4951]. There are three major types of the flow battery can be found on the market where they are Vanadium Redox, Polysulphide Bromide and Zinc Bromine. The operation principle of a flow battery is different from other conventional batteries for example Lead Acid and Lithium-Ion. Its rechargeability is the result of two chemical components that dissolved in the electrolytes of the system which is normally separated by a membrane [45]. The reversible reaction between the two electrolytes allows the potential chemical energy to be stored in the electrolyte solution. The power and energy capacity is determined by the size of the cell while the energy capacity is defined by the volume of the electrolyte. A schematic diagram of a flow battery has been shown in Fig. 15 [52].

6) Supercapacitor: A supercapacitor is designed based on the same physical principles as other conventional capacitors but having a higher area and thinner electrodes. Supercapacitor uses polarized liquid layers between the conducting electrolyte and electrode to increase the overall capacitance [45]. The electrodes of supercapacitors are made of highly effective surface materials, for example, porous carbon and carbon aerogel [53]. The two electrodes of the supercapacitor allow a potential to be applied across its cell which presents two double layers in it. There will be an ionpermeable separator being installed between the electrodes to allow the flows of an ion from the electrolyte but blocks all electrical contact. This type of storage can suppress fast wind power fluctuations within a short time frame. However, it is having a lower energy density in comparison with other conventional batteries but comes with a higher initial cost. Thus, it can be integrated with the battery system as a support for the wind turbines instead of stand-alone as shown in Fig. 16 [54].
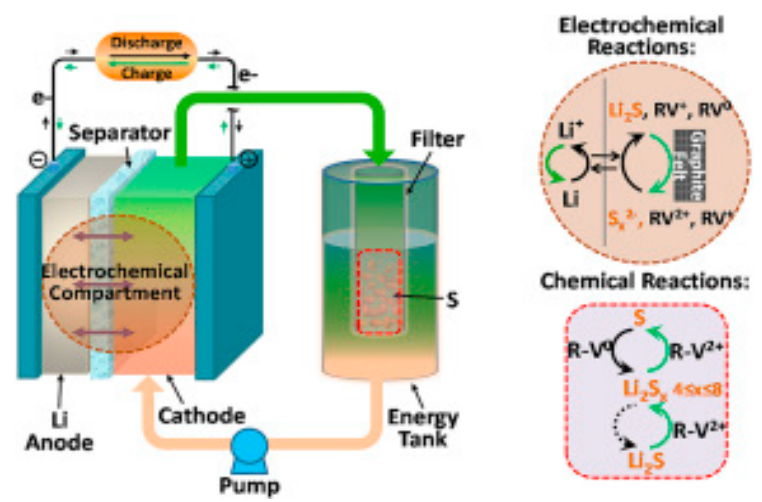

Fig 15. Schematic Diagram of the Flow of Discharge for a Flow Battery.

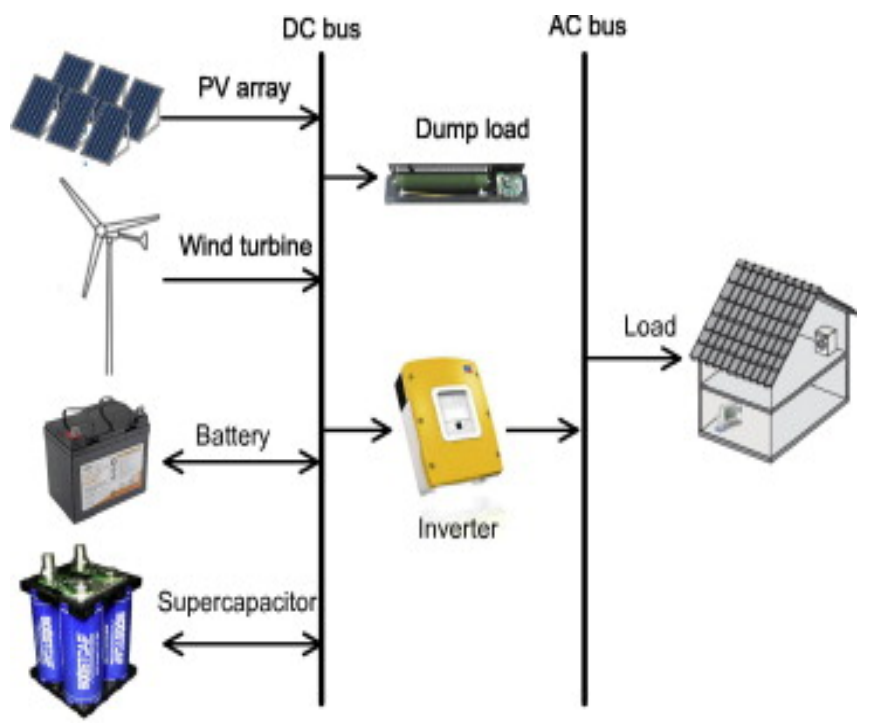

Fig 16. Sample Implementation of Supercapacitor with Battery Storage for Renewable Energy System.

\section{CONCEPT OF MICROGRID}

Microgrid (MG) is an adjacent section of the main grid which can be formed in either single or multiple distributed generation (DG) units to provide sufficient power for the heavy load consumption within the grid [55]. Aziz et al., [56]stated that micro-grid is the integration of several distributed energy resources (DERs) that interconnected to each other to produce the maximum amount of electric power to a group of consumers when it operated as an island and switching the power with existing grid under grid-connected mode. Fig. 17 shows the overall structure of the micro-grid [56]. A microgrid can be operated in the grid-connected mode or autonomous mode when it is connected to or disconnect from the main grid. It usually located at any site in the grid system to enhance system reliability and efficiency. Hatziargyriou et al., [57] agreed that a micro-grid can be operated during gridconnected mode or autonomous mode when the system is disconnected from the main grid due to the faults occur in the system. 


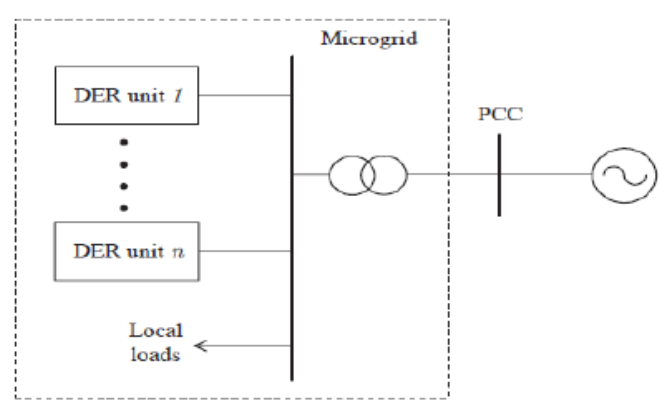

Fig 17. Micro-Grid Structure Formed by a Group of DER Units and Local Loads.

\section{A. Power Control Strategies}

Due to the intermittent characteristic of wind energy, the demand response (DR) is implemented into the wind energy generation system to enhance the grid system by controlling the energy consumption in the grid, maintaining its voltage profile and providing reliable energy for micro-grid [55]. This article had mentioned that the micro-grid can be used to improve power quality by regulating voltage profile, reducing harmful emissions and supplying consumers with low-cost energy supply [57]. Demand response devices with a storage system can be used to regulate the frequency caused by the intermittency of the wind [58]. With this demand response, the energy consumption is reduced during peak hours and the remained energy is shifted for off-peak hours used [55]. Besides, the consumers can incorporate with the system's producers through shifting load profiles to get incentives concerning the electricity price. This obviously would promote economic benefits for both consumers and utilities by reducing the capital investment cost and mitigate the rate of grid maintenance.

Consortium for Electric Reliability Technology Solutions (CERTS) micro-grid is one of the alternative ways to improve system efficiency by integrating more distributed energy resources (DERs) into the grid system [59]. In CERTS microgrid, there are two components which are the static switch and micro source. The static switch is used to autonomously isolate the micro-grid from any disturbances whereas the micro source is used to power on the disconnected/isolated micro-grid using a power- frequency droop controller [59]. This is to ensure that new micro sources can be added to the existing system without causing any interruption to the system and each of the controllers can respond to the system changes. Fig. 18 shows the use of a static switch in the micro-grid system [59]. Under isolated grid mode, each micro source in the system must be able to autonomously respond to the system changes by adopting the local droop controllers for voltage and frequency regulation [58]. The author in [57] stated that the micro source controller controlled the voltage and frequency of the microgrid using the local information where it will execute the demands from a micro-grid central controller (MGCC) when the system is connected to the main grid whereas it will perform grid's optimization and load tracking autonomously when the system is being disconnected or isolated from the main grid [57]. The local load controller (LC) is installed at the controllable load and used for load management by providing the capability for load control with the instruction command from MGCC. Furthermore, the Micro-grid Central Controller (MGCC) is used to maximize the grid value and optimize its operations [57,60]. In this controller, the amount of energy supply will be drawn from the distribution system based on the electricity's prices in the market.

Besides that, this paper has stated two types of control strategies which are centralized control and decentralized control [58]. The decentralized control is the control of the system autonomously based on voltage and frequency measurement in a power system. In this case, a controller is used to generate maximum output power for the demandsupply [57]. The frequency restoration can be carried out by the application of decentralized proportional-integral frequency control. However, the errors in measurement may happen due to the application of control integral part to multiple resources. And thus, it is recommended to apply an integral part to the only single resource when there is no load sharing in the system [58]. Centralized control can be performed by sending control signals to different distributed energy resources through a series of communication channels that can be controlled from the control center. It is usually adopted with demand response to compensate for wind uncertainty. In this case, a low- pass filter is implemented in this control system to drive the slow changes of the power signal. The energy gained from the wind system will supply to distributed energy resources for the compensation due to the wind variability. The synchronous frequency control at the generator site is used to balance the uncompensated variable load and the wind by the centralized control system. During the contingencies condition when the generator is down, the frequency control will be carried out by the decentralized droop controllers [58]. A centralized microgrid control system is typically built up with hierarchical control system architecture which consists of three operation layers including local micro source controller (MC) and load controller (LC), microgrid system central controller (MGCC) and distribution management system (DMS) [60]. The operation of MC, LC and MGCC had been mentioned previously. The distribution management system (DMS), also known as the distribution network operator (DNO) is responsible for the management of medium channel and low voltage area in micro-grid [57]. The DMS can be used to maintain the power quality within a stable and allowable limit in which it is controllable by the system operator [61]. Fig. 19 shows the hierarchical control system architecture of centralized micro-grid [62].

Moreover, in terms of cost-effective, the doubly-fed induction generators (DFIGs) can be used to provide sufficient energy supply. For the DFIGs based wind power system, the stator is directly connected to the grid while the rotor winding is connected through the slip rings to a back- to- back converter [56]. However, there are significant issues such as static and dynamic issues that need to be considered in this case. The static issues will be the profitability of distribution system operators (DSOs) based on the installation of DER. Hence, the location and sizing of DERs would be the main concern for the placement of DFIGs wind turbine in the micro-grid as it would have a direct impact on the DSOs' profit. On the other hand, for the dynamic issues, the IEEE standard 1547 was implemented to ensure the safety of the distribution systems. In 
this rule, it protects the systems by tripping and disconnecting the DERs from the grid for a certain period whenever the voltage or frequency is running out of the range [56]. Fig. 20 shows the voltage disconnection requirement by IEEE Standard 1547 [56].

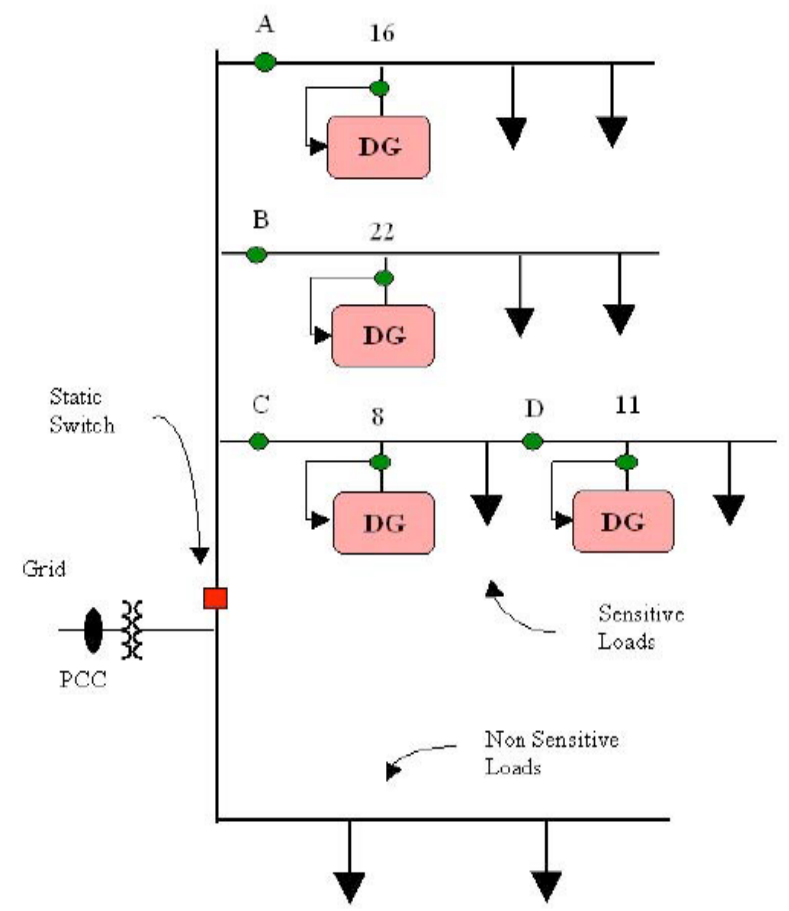

Fig 18. Use of Static Switch in Micro-Grid.

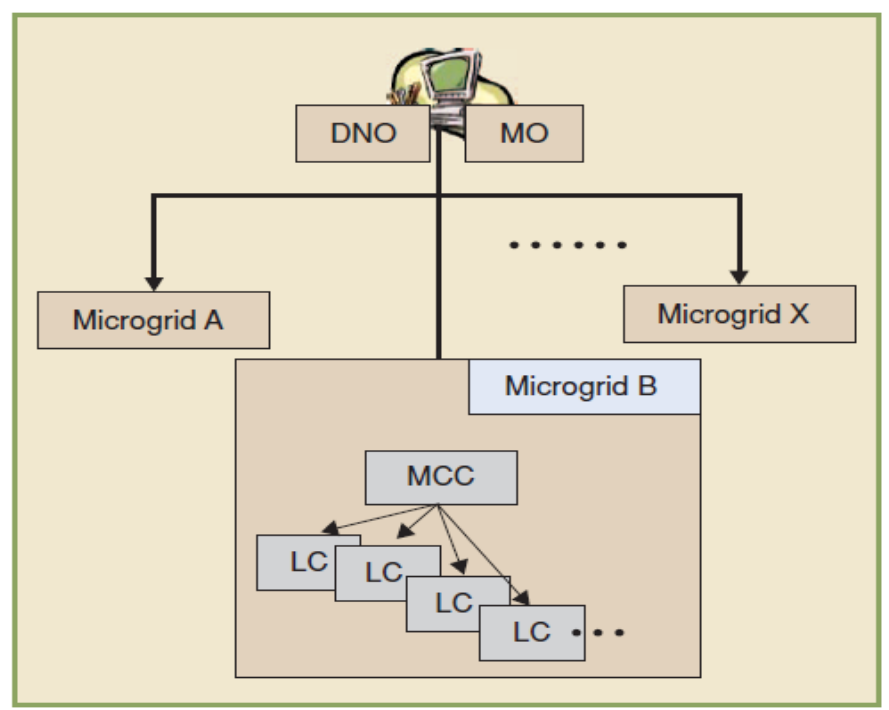

Fig 19. Hierarchical Control System Architectures.

\begin{tabular}{l|c}
\hline \multicolumn{1}{c|}{ Voltage Range (p.u.) } & Clearing time (sec) \\
\hline $\mathrm{V}<0.5$ & 0.16 \\
\hline $0.5 \leq \mathrm{V}<0.88$ & 2.00 \\
\hline $1.1<\mathrm{V}<1.2$ & 1.00 \\
\hline $\mathrm{V} \geq 1.2$ & 0.16 \\
\hline
\end{tabular}

Fig 20. Voltage Disconnection Requirements by IEEE Standard 1547.

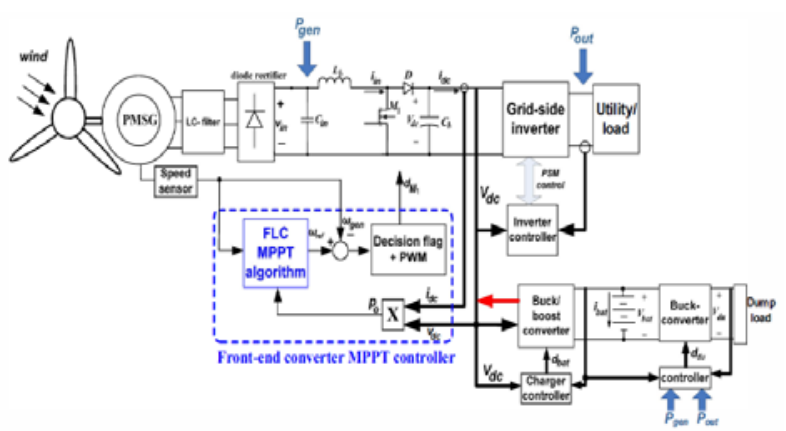

Fig 21. Front-End Converter MPPT Controller in the Wind Power System.

In [63], the authors proposed a control strategy based on the fuzzy logic controller to control the maximum power point tracking (MPPT) in the wind power system that connected to the low voltage grid. In this control system, there are two inputs and one output where the inputs are delta voltage and wind speed and the output is the duty cycle. The duty cycle is the amount of the pulse modulation that used to trip the boost converter to achieve the optimum voltage rating. As for the simulation results, it shows that the wind turbine system with MPPT controller can supply the power at its maximum ratings at a constant voltage and frequency [63]. Hui, J. and P. K. Jain also agreed that the generator load can be varied by monitoring the duty cycle of the front- end boost converter to achieve the MPPT and Fig. 21 shows the wind power system using the front- end converter MPPT controller [64].

\section{B. Energy Management Strategies}

As the cost and efficiency of the grid operation are the main concerns, the energy management system plays an important role in the control system of the micro-grid [65]. Katiraei et al., [62], stated that a fast response to energy management strategy (EMS) is essential for a micro-grid that is operated under autonomous mode with more than two distributed energy resource units. It is because of the multiple DER units with different power capacities and lack of infinite bus in the system. Thus, the purpose of EMS is to distribute the real and reactive power equally among the DER units and restore the frequency by determining the power setpoints.

The use of energy management and power control (EMPC) systems in a wind-generated micro-grid especially at the low wind speed area has been investigated [66]. The energy management and power control (EMPC) system are used to stabilize the start-up- shutdown processes in each turbine in order to provide the maximum output to the grid that located in low wind speed area and also to protect the mechanical parts of the equipment from breakdown due to the frequent start-up and shutdown. The system is becoming less cost-effective as there are several parameters involved. To achieve cost-effective, a more adaptable control strategy called fuzzy- logic control is used [66]. These FLCs can provide maximum output power to the grid and ensure less mechanical stress on the mechanism parts yet to expand its lifespan. In [67], the authors proposed the use of the Economic model Predictive Control (EMPC) scheme to perform economic optimization in the operational costs of micro-grid. Fig. 22 and 23 shows the proposed EMPC system in wind power system at low wind speed region and the flowchart of FLCs in the system [66]. 


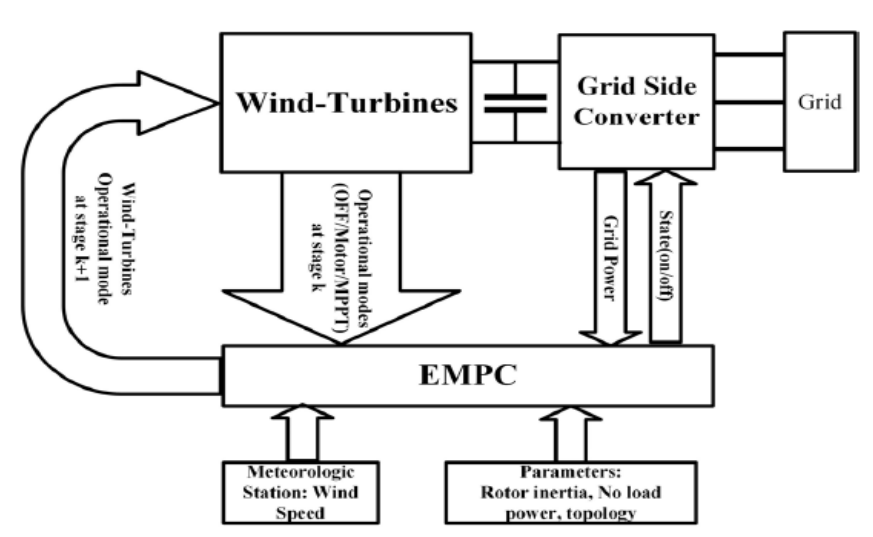

Fig 22. Proposed EMPC System for Low Wind Speed Area.

Other than that, the authors had proposed an energy management optimization model of wind- turbine based DC microgrid with batteries as the energy storage system [68]. This had overcome the intermittent characteristic of wind power in DC microgrid. The optimization of the energy resources can be achieved through the load and generation forecasting that related to electricity's price. Apart from that, the battery energy storage system (BESS) is proposed to be installed at the generation side to stabilize the uncertainty of wind speed [69]. This system can regulate the output power by incorporating other generators in the grid system to provide a balanced power supply. The energy produced during the strong wind will be stored in this BESS system and the stored energy will be supplied for grid used whenever the area is to be detected in the low wind speed situation.

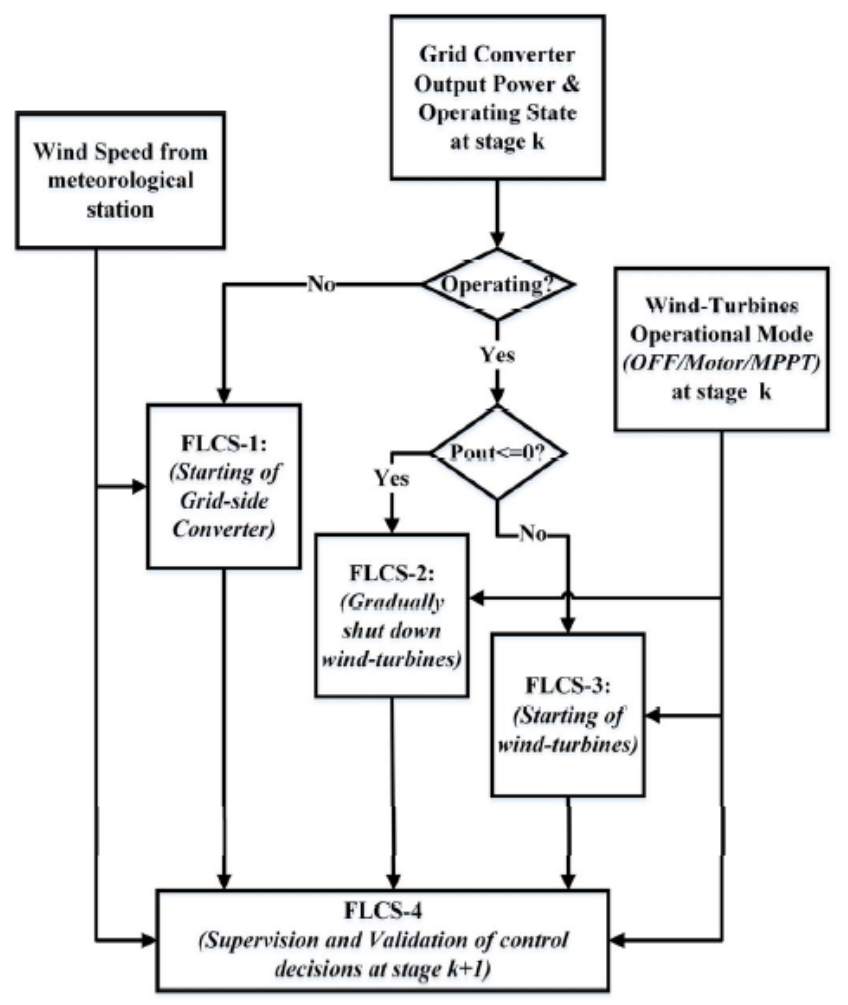

Fig 23. Flowchart of FLCs.

\section{GRID INTEGRATION OF Wind TURBINE GENERATOR}

\section{A. Grid Connection of Wind Turbine Generator}

Wind Turbine Generator (WTG) can be classified into a few types of connections with a power grid base on their different speed controls. They are Type 1, Type 2, Type 3 and Type 4 WTG. Camm et al. stated that Type 1 WTG has its rotating speed fixed to the power grid frequency and its connection to the power grid is shown in Fig. 24(a) [70]. It usually implemented on squirrel-cage induction generator (SCIG) with soft starter and parallel capacitor bank across the step-up transformer connected to the grid side. The soft starter and parallel capacitor bank eliminate the effects of consuming reactive power and drawing large currents because of its excitation field produced by the machine. The rotating speed of Type 2 WTG can be varied but it is limited. Fig. 24(b) shows the connection of Type 2 WTG to the main supply grid which is usually used in the wound-rotor induction generator [71]. The machine has a parallel connection with a variable resistor to maintain the power when gust and a capacitor bank to supply reactive power too.

The implementations of Type 3 and Type 4 WTG connections are getting more popular in recent years. Both Type 3 and Type 4 WTG are variable speed controlled. Type 3 WTG is usually implemented with a doubly-fed induction generator (DFIG) whereas Type 4 WTG is usually implemented with a permanent magnet synchronous generator (PMSG). The difference between Type 3 and Type 4 WTG is the connection and control of the power converter. Fig. 25(a) and (b) show the connection of Type 2 and Type 3 WTG with the power grid [70,72]. Type 3 WTG is partially controlled whereas Type 4 WTG is fully controlled. The control method and capabilities of Type 3 WTG will be further discussed in Section 3. For Type 4 WTG, it is series connected with two back-to-back inverters with a Direct Current (DC) link in between them, to the power grid. The inverters are responsible for the control of power supply and regulate its voltage so that power grid synchronization and stability could be achieved. Zou and He agree with the statement and proposed a control model for it in [72]. The controller at the machine side controls the inverter to generate power from the wind turbine whereas the controller at the grid side controls the inverter to regulate the voltage supplied to the grid to remain synchronized. This type of WTG and Type 3 WTG is widely implemented as it can control the speed of the wind turbine to generate optimum power. Optimum power supply to the grid is important to reduce the case of power fluctuation happens on the power grid. Putri et al. emphasize on optimum power generation for PMSG and the proposed control method in [73].

\section{B. Capabilities of Wind Turbine Generators}

The voltage control of WTG is usually done by the centralized wind farm controller. It controls the amount of voltage supplied to the power grid. Type 1 and Type 2 WTG do not have the capabilities of voltage control whereas Type 3 and Type 4 do have it [70]. This is because Type 1 and Type 2 WTG require the capacitor bank to supply reactive power and correct its power factor. Type 3 and Type 4 can supply reactive power by itself. On the other hand, it means that the voltage can be controlled at a fixed terminal voltage and active power 
with varied reactive power. Besides, WTG needs to have reactive power capabilities so that the desired connection could be achieved in Wind Power Plant (WPP) at a specific range of power factors. The reactive power capabilities of Type 1 and Type 2 WTG is done by the capacitor bank installed together with the WTG [70-78]. The capacitor bank can set to 0.98 leading of the rated power to compensate for the no-load condition or 0.98 lagging of the rated power to compensate for the full-load condition. Type 3 WTG normally has 0.90 leading to 0.95 lagging power factor. Type 4 WTG has a wide range of power factor control since it has the control of current through the grid side converter [70, 79-84].

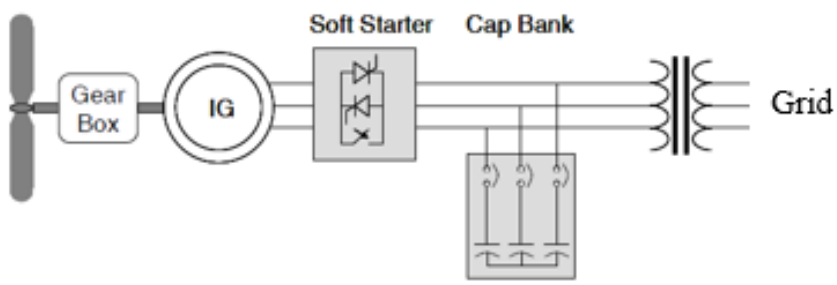

(a)

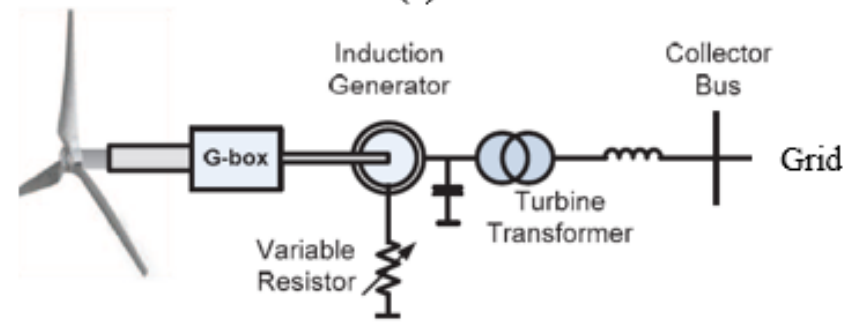

(b)

Fig 24. Connection of WTG to the Grid in Early-Stage (a) Type 1 WTG (b) Type 2 WTG.

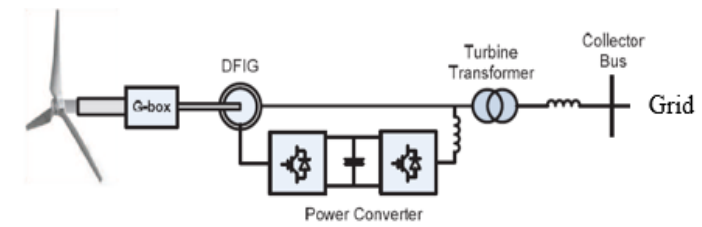

(a)

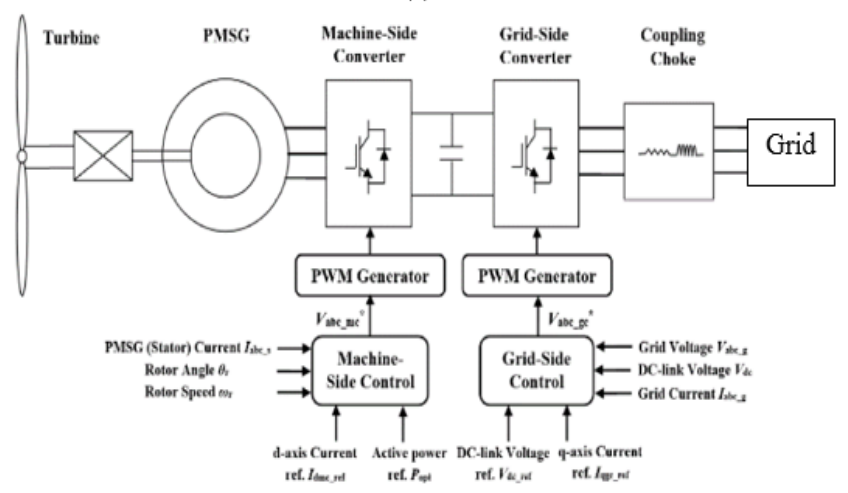

(b)

Fig 25. Modern Connection used between WTG and Power Grid (a) Type 3 WTG (b) Type 4 WTG.
There are a few problems regarding the stability of the grid met when connecting the WTG to the main grid. They include overvoltage in the network between WTG and grid, fluctuation of WTG output power, fluctuation of voltage in the weak distribution grid and more [74]. These problems are related to each other. Overvoltage usually occurs when the wind power generated is at its maximum and the power requirement by the load is at its minimum. Because of the variable wind speed and wind shear, the power fluctuation of WTG creates an aerodynamic power fluctuation. Power fluctuation can cause voltage fluctuation in a weak distribution grid and result in power quality issues. Thus, the control of voltage and power for WTG is important to maintain the stability of the power grid. This is also the reason why the popularities of implementing Type 3 and Type 4 WTG increase rapidly in the past decades. Besides, active voltage management by restricting the active power and compensate reactive power is one of the solutions to solve the overvoltage problem [74, 8591]. Restriction of active power reduces the voltage supplied to the grid and reactive power compensation limits the voltage at the terminal of WTG.

\section{Doubly Fed Induction Generator}

1) Proposed Model: Doubly Fed Induction Generator (DFIG) used Type 3 WTG connection to the power grid. As mentioned previously, it has a parallel connection of power converter or it can be referred to as two back-to-back inverters with a DC link connected in between. Fig. 26 shows the detailed schematic for Type 3 DFIG connection to the power grid proposed by Ledesma and Usaola in [75, 92-101]. Grid side inverter current is used to control active power and reactive power supplied to the grid; rotor side inverter current is used to control electromagnetic torque and excitation of the wind turbine. The voltage level of the DC link connected between two inverters is controlled by the active power of the grid side inverter.

Lei, Mullane, Lightbody and Yacamini also agree with Ledesma and Usaola as they suggested the same connection for DFIG to the power grid. Fig. 27(a) below shows the connection between the DFIG and power grid which is approximately the same compared to Fig. 26 [76]. The model proposed by Lei, Mullane, Lightbody and Yacamini assumed that both inverters to be ideal in their simulations. The researchers implemented two back-to-back voltage fed Pulse Width Modulation (PWM) inverter, with a DC link connected in between connecting the WTG to the supply grid. The inverters have the same functions as before which are controlling the power output to the grid. This can be done by controlling the switching frequency of the Insulated Gate Bipolar Transistors (IGBT) in the inverters. It can be as effective as connecting to a voltage source controller as shown in Fig. 27(b). The researcher replaced the use of inverters to a voltage source controller in their simulation [76, 102-103]. 


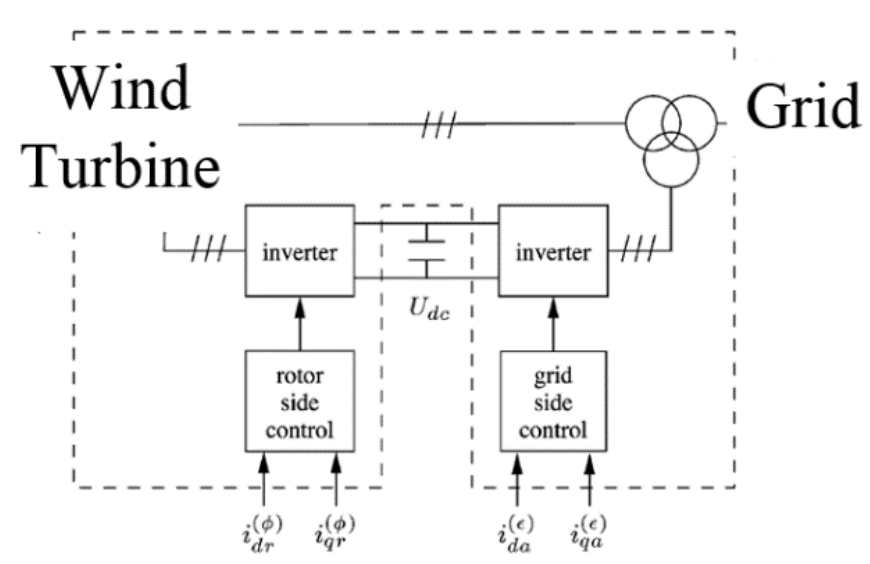

Fig 26. Connection of DFIG with the Power Grid.

$\mathrm{Xu}$, Yao and Sasse proposed the use of voltage source converter (VSC) for DFIG in High Voltage Direct Current (HVDC) transmission in [77]. The large size DFIG wind farms are implemented and the power generated is transmitted to the power grid via two DC cross-linked polyethylene (XLPE) cables. A generator side VSC and a grid-side VSC is connected at both ends of the DC XLPE cable connecting the wind farm and power grid. A high pass filter is installed at both VSC to filter away high-frequency harmonics. Fig. 28 shows a clearer vision of the connection of the DFIG with the power grid proposed [77]. The voltage level and frequency generated by the wind farm are controlled by the generator side VSC whereas the voltage level supplied from the generator side is controlled by the grid side VSC at the power grid. To ensure the system operates normally, the voltage across the DC XLPE cable must be maintained so that it has a balanced power flow [77].

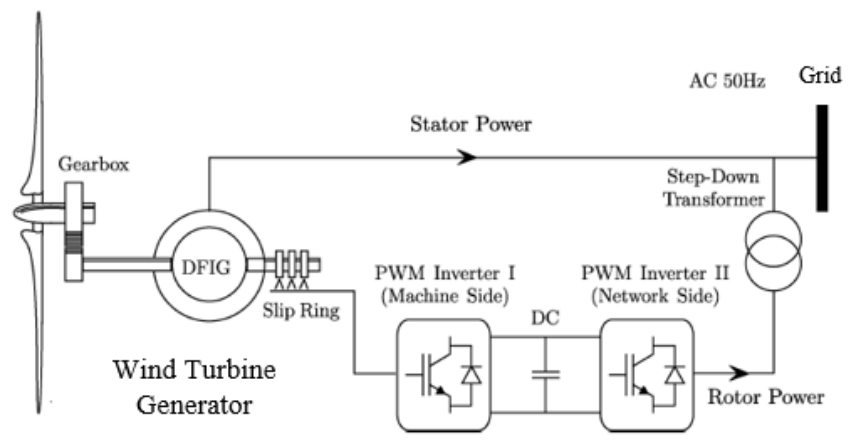

(a)

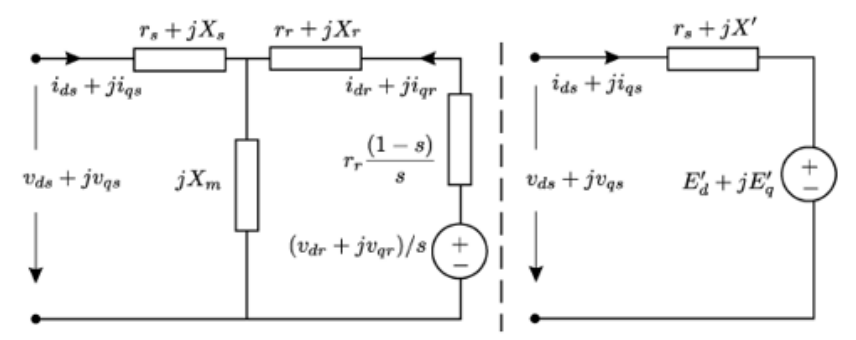

(b)

Fig 27. (a) Connection of DFIG to grid (b) Voltage Source Controller used to Replace two PWM Inverters in Simulation.

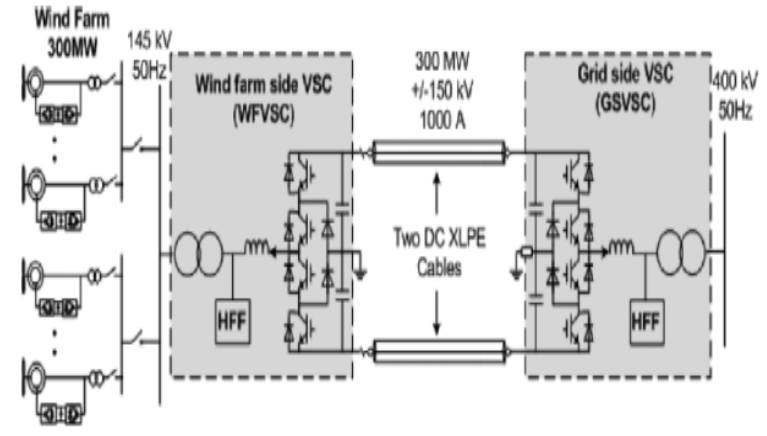

Fig 28. DC XLPE Cables with VSC at both Ends Connecting Large Size DFIG Wind Farm and Power Grid Together.

The first proposed model only consists of a variable-speed wind turbine control system, wind torque and mechanical system for completion in wind turbine modeling and assumed instantaneous control of current in inverters. The researchers also reduce the complexity in the simulation of the proposed model by using an integration step of $10 \mathrm{~ms}$ [75, 104]. The second proposed model allows the simulation of torque and reactive power controlled independently in a simple way. This model is suitable to analyze large size DFIG power systems and is efficient but not suitable for power converter study as both the PWM inverters were replaced by a voltage source controller to ease the simulation. The third proposed model provides advantages of fully controlled power flow of the system, can have long transmission distance regardless of the charging currents caused by the cable and high efficiency in the DC XLPE transmission cables. This proposed model also gives satisfactory results in operation and performance when no-fault occurred as shown in [77].

2) Fault Ride-Through Capability: Since DFIG is getting more popular to be implemented among other WTGs, it is important to study its behavior when the fault occurred. The sensitivity of DFIG to disturb the power grid when the fault occurred is very high. The control scheme and protection scheme is designed to allow a low voltage or fault ridethrough of DFIG and protect its components. Crowbar protection is one of the protection schemes that is usually used for DFIG during fault ride through. This protection scheme is suggested by Sava et al. and Lopez, Gubia, Olea, Ruiz and Marroyo for protecting DFIG when the fault occurred and both agree that this protection scheme lost control in the reactive power when the protection is on in [78, 79]. It lost control of reactive power because the rotor side converter is blocked and thus causing the WTG is disconnected from the grid when the protection is on. The rotor side converter will only be gained control after the protection of the crowbar is off. The connection of crowbar protection to DFIG as mentioned in [79] is shown in Fig. 30(a) below. The crowbar protection mainly consists of a resistor and active switch device connected across the rotor side. Activation of crowbar protection depends on the DC link voltage level of the backto-back inverters. When there is a fault occurred, the overvoltage or overcurrent will not destroy the rotor circuits but only activate and pass through the crowbar. 


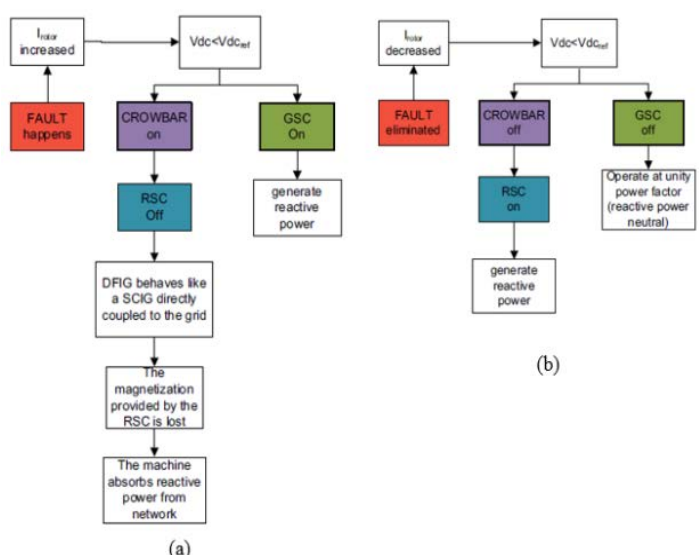

Fig 29. (a) Control Scheme when a Fault Occurs (b) Control Scheme when a Fault is Removed.

However, consideration of reactive power compensation is important in the system. Sava et al. have developed a control method for reactive power generation by grid side converter when the crowbar protection is on as shown in Fig. 29 [78]. The grid side converter will be controlled to supply reactive power when the crowbar protection is on. Furthermore, there are alternatives like an injection of current that opposes the natural flux which can protect the components in the rotor side converter without disconnecting it. Xiang, Ran, Tavner and Yang proposed the injection of opposed stator flux to decrease the rotor current [80]. The decreased amount of rotor current will protect the rotor side converter from any thermal destruction. But, the current required to oppose it usually is very large which happens only severe voltage sag as described in [79]. Thus, Lopez, Gubia, Olea, Ruiz and Marroyo suggest a strategy of combining the crowbar protection and oppose current injection for fault ride-through of DFIG [79]. Crowbar protection activates instantly when a fault occurs and demagnetization of the machine happens at the same time. After the machine is partially demagnetized, crowbar protection is off and the inverter injects the opposing current to generate reactive power. This method only reduces the activation period of the crowbar protection which means that there will still be a very short period without generating reactive power. This method accelerates the injection of reactive power when the fault occurred as shown in Fig. 30(b) [79].

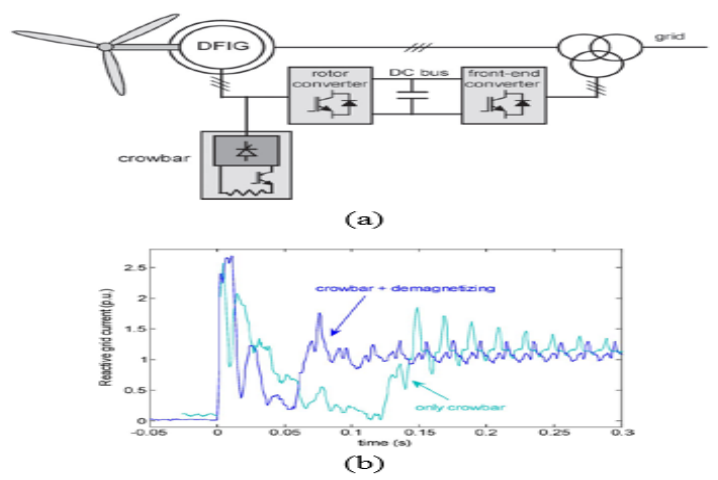

Fig 30. (a) Crowbar Protection Added to DFIG (b) Injection of Reactive Current into the Power Grid.
Yao, Li, Liao and Chen agree that crowbar can protect the rotor side converter by disconnecting the rotor circuit and short it with the resistor in crowbar [81]. They stated that the DC link voltage between two back-to-back inverters will be fluctuated and affect the control of the rotor current when the rotor circuit is connected back to the system (fault has been removed) in [81]. It can be said that the DC link voltage is important to maintain the stability of grid-supplied voltage. Its stability is maintained through balance active and reactive power supply to the power grid. The researchers proposed the improved grid side converter control strategies when the grid voltage is constant and when there is voltage sag happens in [81]. When the grid voltage is constant, the controller will keep on checking current at the grid side converter to ensure the stability of DC-link voltage. When there is a voltage sag happens, grid voltage will decrease rapidly and lead to a huge difference in power supplied. This will cause the fluctuation of DC-link voltage. Hence, the researchers introduced a control loop for a single inner current to limit the fluctuation effectively and it is proven in [81] that both control strategies are validated. The proposed control loop will regulate the grid current rapidly from the semiconductor converter to reduce the difference in output power. This helps in reducing DC link voltage fluctuation and limit the DC link voltage. But, this control strategy when voltage sag happens is not applicable if severe voltage sag happens at the power grid.

3) Reactive Power Support: As mentioned previously, the voltage control capability of WTG is important to maintain power grid stability. DFIG has the same voltage control capability as PMSG which is by controlling the generation of reactive power. As stated in [82], Santos-Martin, Arnaltes and Rodriguez Amenedo emphasized the importance of having reactive power capability for WTG required by the power grid when connecting WTG to the power grid. The reactive power usually generated by the stator and grid side inverter in the WTG. This reactive power generated is then fed into the power grid. Nevertheless, the grid side inverter has a unity power factor and this makes the only stator contributes to the reactive power supply in a commercial system. The researchers also stated that the voltage supplied to the power grid can be expressed in terms of reactive power in [82]. The stability of the power grid could be maintained if effective control of reactive power generation is established in WTG.

Control of both rotor side inverter and grid side inverter to generate reactive power is possible for voltage control purpose and this is suggested in [83]. Under the uncoordinated condition, both inverters are working either to supply or absorb reactive power. One of the inverters should absorb the reactive power generated by the other to prevent any extra current circulates in the circuit that will cause thermal destruction to the inverters. Either rotor side inverter or grid side inverter is used for reactive power generation to regulate the voltage supplied to the power grid and another of them will not work under coordinated condition. The rotor side inverter will not supply reactive power when the crowbar protection is on [83]. Since the rotor side inverter will be disconnected when crowbar protection is on, the grid side inverter is responsible for the supply of reactive power to the power grid. 


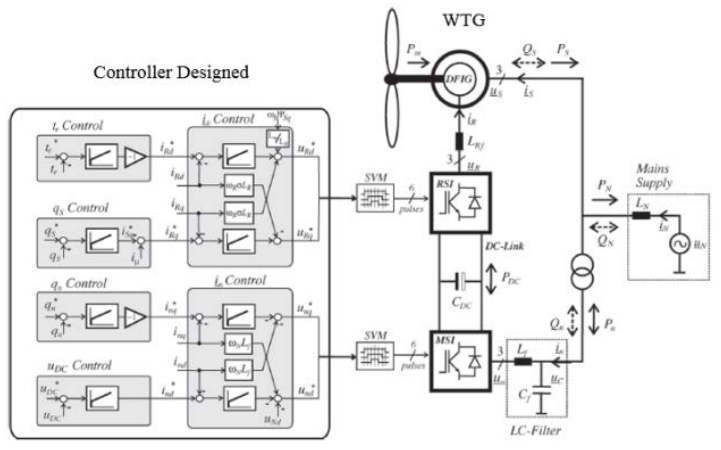

Fig 31. Rotor Side Inverter and Grid Side Inverter Control Scheme to Regulate Reactive Power

The maintenance of power grid stability is important when it has more developments and implementations in WTG. This can be achieved through voltage regulation by generating reactive power supply to the power grid. Rabelo, Hofmann, da Silva, de Oliveira and Silva also agree with the statements above and they proposed a controller designed to regulate voltage by supplying reactive power adequately using the rotor side inverter and grid side inverter [84]. Adequate reactive power generation increases system efficiency. The controller designed used linear control techniques and some improvements were made according to its limitations. The controller implemented is shown in Fig. 31 above and the detailed control method can be referred to in [84]. The control scheme allows the control of reactive power to be generated by both inverters to compensate it for the system. This reduces the power loss in the system and hence increases its efficiency.

\section{PROSPECTS AND LIMITATIONS}

Implementation of the wind power system in Malaysia does not give a lot of benefits. This is because wind speed in Malaysia is generally low and the direction of wind flow is unstable when compared with other countries. Wind power generated is insufficient to support the power grid. Ineffective control of wind turbine generator will lead to fluctuation of voltage and power supplied. But, these problems could be overcome by combining another source of energy in power generation. One of them is combining solar power with wind power in grid integration. Wind power can be used as a backup generator for solar power or vice versa to maintain a stable power generation. There are a few locations in Malaysia where the wind speed is higher and stable. These locations are suitable for this solar wind hybrid system. These power generations are also environment-friendly and sustainable when compared with the non-renewable energy used in Malaysia earlier like fossil fuels and natural gas.

\section{CONCLUSIONS}

This research report reviewed different parts of the wind power system which include wind turbines, energy storage, microgrid and grid integration. It has been found that the implementation of HAWT is not suitable for Malaysia due to unstable wind flow direction. VAWT can be considered as it has omnidirectional characteristics. The use of an energy storage system in the wind power system allows energy to be used in a "smarter" way. The power generated can be stored or supplied depends on load demand. The reliability of the wind turbine system in microgrid integration mainly depends on power control and energy management. Both strategies are important to maximize the efficiency of the microgrid. Type 3 and Type 4 WTG would be suggested for grid integration as they have control in wind turbine rotation. They allow the control of voltage and reactive power supplied to the grid for maintaining grid stability. Effective control of reactive power generation needs to be found in the future work to maintain the stability of the power grid in WTG.

\section{REFERENCES}

[1] G. Ahmad and U. Amin, "Design, construction and study of small scale vertical axis wind turbine based on a magnetically levitated axial flux permanent magnet generator," Renewable Energy, vol. 101, pp. 286292, 2// 2017.

[2] Z. Cheng, H. A. Madsen, W. Chai, Z. Gao and T. Moan, "A comparison of extreme structural responses and fatigue damage of semi-submersible type floating horizontal and vertical axis wind turbines," Renewable Energy, vol. 108, pp. 207-219, 8// 2017.

[3] Z. Cheng, H. A. Madsen, Z. Gao and T. Moan, "A fully coupled method for numerical modeling and dynamic analysis of floating vertical axis wind turbines," Renewable Energy, vol. 107, pp. 604-619, 7// 2017.

[4] A. O. Onol and S. Yesilyurt, "Effects of wind gusts on a vertical axis wind turbine with high solidity," Journal of Wind Engineering and Industrial Aerodynamics, vol. 162, pp. 1-11, 3// 2017.

[5] K. H. Wong, W. T. Chong, N. L. Sukiman, S. C. Poh, Y.-C. Shiah and C.-T. Wang, "Performance enhancements on vertical axis wind turbines using flow augmentation systems: A review," Renewable and Sustainable Energy Reviews, vol. 73, pp. 904-921, 6// 2017.

[6] A. Rezaeiha, I. Kalkman and B. Blocken, "Effect of pitch angle on power performance and aerodynamics of a vertical axis wind turbine," Applied Energy, vol. 197, pp. 132-150, 7/1/ 2017.

[7] X. Jin, G. Zhao, K. Gao and W. Ju, "Darrieus vertical axis wind turbine: Basic research methods," Renewable and Sustainable Energy Reviews, vol. 42, pp. 212-225, 2// 2015.

[8] F. Toja-Silva, A. Colmenar-Santos and M. Castro-Gil, "Urban wind energy exploitation systems: Behaviour under multidirectional flow conditions-Opportunities and challenges," Renewable and Sustainable Energy Reviews, vol. 24, pp. 364-378, 8// 2013.

[9] "HAWT versus VAWT: Small VAWTs find a clear niche," Refocus, vol. 4, no. 4, pp. 44-46, 7// 2003.

[10] G. M. H. Shahariar and M. R. Hasan, "Design \&amp; construction of a Vertical Axis Wind Turbine," in 2014 9th International Forum on Strategic Technology (IFOST), 2014, pp. 326-329.

[11] S. M. Camporeale and V. Magi, "Streamtube model for analysis of vertical axis variable pitch turbine for marine currents energy conversion," Energy Conversion and Management, vol. 41, no. 16, pp. 1811-1827, 11/1/ 2000.

[12] M. A. Biadgo, A. Simonović, D. Komarov and S. Stupar, "Numerical and analytical investigation of vertical axis wind turbine," FME Transactions, vol. 41, no. 1, pp. 49-58, 2013.

[13] A. T. Zhuga, B. Munyaradzi and C. Shonhiwa, "Design of alternative energy systems: A self-starting Vertical Axis Wind Turbine for standalone applications (charging batteries)," SPONSORS, p. 72, 2006.

[14] M. Ragheb, "Vertical axis wind turbines," University of Illinois at Urbana-Champaign, vol. 1, 2011.

[15] Q. a. Li, T. Maeda, Y. Kamada, J. Murata, K. Furukawa and M. Yamamoto, "The influence of flow field and aerodynamic forces on a straight-bladed vertical axis wind turbine," Energy, vol. 111, pp. 260271, 9/15/ 2016.

[16] Q. a. Li et al., "Wind tunnel and numerical study of a straight-bladed vertical axis wind turbine in three-dimensional analysis (Part I: For predicting aerodynamic loads and performance)," Energy, vol. 106, pp. 443-452, 7/1/ 2016. 
[17] M. F. Ismail and K. Vijayaraghavan, "The effects of aerofoil profile modification on a vertical axis wind turbine performance," Energy, vol. 80, pp. 20-31, 2/1/ 2015.

[18] Z. Cheng, H. A. Madsen, Z. Gao and T. Moan, "Effect of the number of blades on the dynamics of floating straight-bladed vertical axis wind turbines," Renewable Energy, vol. 101, pp. 1285-1298, 2// 2017.

[19] I. Ross and A. Altman, "Wind tunnel blockage corrections: Review and application to Savonius vertical-axis wind turbines," Journal of Wind Engineering and Industrial Aerodynamics, vol. 99, no. 5, pp. 523-538, 5// 2011.

[20] S. Eriksson, H. Bernhoff and M. Leijon, "Evaluation of different turbine concepts for wind power," Renewable and Sustainable Energy Reviews, vol. 12, no. 5, pp. 1419-1434, 2008.

[21] C.-J. Bai and W.-C. Wang, "Review of computational and experimental approaches to analysis of aerodynamic performance in horizontal-axis wind turbines (HAWTs)," Renewable and Sustainable Energy Reviews, vol. 63, pp. 506-519, 9// 2016.

[22] B. Gaunt and D. A. Johnson, "Wind turbine performance in controlled conditions: Experimental results," International Journal of Green Energy, no. just-accepted, 2012.

[23] Shikha, T. S. Bhatti and D. P. Kothari, "Early Development of Modern Vertical and Horizontal Axis Wind Turbines: A Review," Wind Engineering, vol. 29, no. 3, pp. 287-299, 2005.

[24] F. Kanyako and I. Janajreh, "Implementation and economical study of HAWT under different wind scenarios," Sustainable Cities and Society, vol. 15, pp. 153-160, 7// 2015.

[25] M. Ó. Óskarsdóttir, "A General Description and Comparison of Horizontal Axis Wind Turbines and Vertical Axis Wind Turbines," 2014.

[26] J. Manwell, J. McGowan and A. Rogers, "Aerodynamics of wind turbines," Wind Energy Explained: Theory, Design and Application, Second Edition, pp. 91-155, 2009.

[27] S. McFadden and B. Basu, "7 - Wind turbine gearbox design with drivetrain dynamic analysis," in Offshore Wind Farms: Woodhead Publishing, 2016, pp. 137-158.

[28] C. Eisenhut, F. Krug, C. Schram and B. Klockl, "Wind-turbine model for system simulations near cut-in wind speed," IEEE Transactions on Energy Conversion, vol. 22, no. 2, pp. 414-420, 2007.

[29] R. Bi, C. Zhou and D. M. Hepburn, "Detection and classification of faults in pitch-regulated wind turbine generators using normal behaviour models based on performance curves," Renewable Energy, vol. 105, pp. 674-688, 5// 2017.

[30] R. Tiwari and N. R. Babu, "Recent developments of control strategies for wind energy conversion system," Renewable and Sustainable Energy Reviews, vol. 66, pp. 268-285, 12// 2016.

[31] A. S. Yilmaz and Z. Özer, "Pitch angle control in wind turbines above the rated wind speed by multi-layer perceptron and radial basis function neural networks," Expert Systems with Applications, vol. 36, no. 6, pp. 9767-9775, 8// 2009.

[32] B. Bavanish and K. Thyagarajan, "Optimization of power coefficient on a horizontal axis wind turbine using bem theory," Renewable and Sustainable Energy Reviews, vol. 26, pp. 169-182, 10// 2013.

[33] K. Johnson, L. J. Fingersh, M. Balas and L. Pao, "Methods for increasing region 2 power capture on a variable speed HAWT," in 42nd AIAA Aerospace Sciences Meeting and Exhibit, 2004, p. 350.

[34] P. J. Schubel and R. J. Crossley, "Wind turbine blade design," Energies, vol. 5, no. 9, pp. 3425-3449, 2012.

[35] A. Sedaghat and M. Mirhosseini, "Aerodynamic design of a $300 \mathrm{~kW}$ horizontal axis wind turbine for province of Semnan," Energy Conversion and Management, vol. 63, pp. 87-94, 11// 2012.

[36] M. Ragheb, "Optimal rotor tip speed ratio," Available from NetFiles at the University of Illinois at Urbana-Champaign, Last modified, 2009.

[37] G. C. Venkatesh and S. V. Kulkarni, "Energy yield of passive stall regulated fixed speed wind turbine with optimal rotor speed," Electric Power Systems Research, vol. 76, no. 12, pp. 1019-1026, 8// 2006.

[38] M.-S. Jeong, S.-W. Kim, I. Lee, S.-J. Yoo and K. C. Park, "The impact of yaw error on aeroelastic characteristics of a horizontal axis wind turbine blade," Renewable Energy, vol. 60, pp. 256-268, 12// 2013.
[39] H. Hui, M. Chengxiong, L. Jiming and W. Dan, "Electronic Power Transformer Control Strategy in Wind Energy Conversion Systems for Low Voltage Ride-through Capability Enhancement of Directly Driven Wind Turbines with Permanent Magnet Synchronous Generators (DPMSGs)," Energies (19961073), Article vol. 7, no. 11, pp. 7330-7347, 2014.

[40] W. Shepherd and L. Zhang, "Electricity Generation Using Wind Power," ed: World Scientific, 2011.

[41] H. Li and Z. Chen, "Overview of different wind generator systems and their comparisons," IET Renewable Power Generation, vol. 2, no. 2, pp. 123-138, 2008.

[42] R. Cisneros, F. Mancilla-David and R. Ortega, "Passivity-Based Control of a Grid-Connected Small-Scale Windmill With Limited Control Authority," IEEE Journal of Emerging and Selected Topics in Power Electronics, vol. 1, no. 4, pp. 247-259, 2013.

[43] D. Kumar and K. Chatterjee, "A review of conventional and advanced MPPT algorithms for wind energy systems," Renewable and Sustainable Energy Reviews, vol. 55, pp. 957-970, 3// 2016.

[44] A. Nagliero, R. Mastromauro, V. Monopoli, M. Liserre and A. Dell'Aquila, "Analysis of a universal inverter working in grid-connected, stand-alone and micro-grid," in Industrial Electronics (ISIE), 2010 IEEE International Symposium on, 2010, pp. 650-657: IEEE.

[45] M. Świerczyński, R. Teodorescu, C. N. Rasmussen, P. Rodriguez and H. Vikelgaard, "Overview of the energy storage systems for wind power integration enhancement," in Industrial Electronics (ISIE), 2010 IEEE International Symposium on, 2010, pp. 3749-3756: IEEE.

[46] Z. Huang and G. Du, "Chapter 4 - Nickel-based batteries for mediumand large-scale energy storage A2 - Menictas, Chris," in Advances in Batteries for Medium and Large-Scale Energy Storage, M. SkyllasKazacos and T. M. Lim, Eds.: Woodhead Publishing, 2015, pp. 73-90.

[47] T. Horiba, "Lithium-Ion Battery Systems," Proceedings of the IEEE, vol. 102, no. 6, pp. 939-950, 2014.

[48] Z. Wen, J. Cao, Z. Gu, X. Xu, F. Zhang and Z. Lin, "Research on sodium sulfur battery for energy storage," Solid State Ionics, vol. 179, no. 27-32, pp. 1697-1701, 9/30/ 2008.

[49] S. Dambone Sessa, G. Crugnola, M. Todeschini, S. Zin and R. Benato, "Sodium nickel chloride battery steady-state regime model for stationary electrical energy storage," Journal of Energy Storage, vol. 6, pp. 105115, 5// 2016.

[50] J. L. Sudworth, "The sodium/nickel chloride (ZEBRA) battery," Journal of Power Sources, vol. 100, no. 1-2, pp. 149-163, 11/30/ 2001.

[51] W. Wang, Q. Luo, B. Li, X. Wei, L. Li and Z. Yang, "Recent Progress in Redox Flow Battery Research and Development," Advanced Functional Materials, vol. 23, no. 8, pp. 970-986, 2013.

[52] J. Li, L. Yang, B. Yuan, G. Li and J. Y. Lee, "Combined mediator and electrochemical charging and discharging of redox targeting lithiumsulfur flow batteries," Materials Today Energy, vol. 5, pp. 15-21, 9// 2017.

[53] M. A. Guerrero, E. Romero, F. Barrero, M. I. Milanés and E. González, "Supercapacitors: alternative energy storage systems," Przegląd Elektrotechniczny, vol. 85, no. 10, pp. 188-195, 2009.

[54] T. Ma, H. Yang and L. Lu, "Development of hybrid batterysupercapacitor energy storage for remote area renewable energy systems," Applied Energy, vol. 153, pp. 56-62, 9/1/ 2015.

[55] J. O. Petinrin and M. Shaaban, "A hybrid solar PV/wind energy system for voltage regulation in a microgrid," in 2013 IEEE Student Conference on Research and Development, 2013, pp. 545-549.

[56] T. Aziz, S. I. M. Salman, M. S. Islam, A. Razzaq, R. A. Chowdhury and M. I. H. Mitun, "Integration of wind energy system in microgrid considering static and dynamic issues," in 2015 International Conference on Electrical Engineering and Information Communication Technology (ICEEICT), 2015, pp. 1-5.

[57] N. D. Hatziargyriou, A. Dimeas, A. G. Tsikalakis, J. A. P. Lopes, G. Karniotakis and J. Oyarzabal, "Management of microgrids in market environment," in 2005 International Conference on Future Power Systems, 2005, pp. 7 pp.-7. 
[58] S. Lu et al., "Control strategies for distributed energy resources to maximize the use of wind power in rural microgrids," in 2011 IEEE Power and Energy Society General Meeting, 2011, pp. 1-8.

[59] P. Piagi and R. H. Lasseter, "Autonomous control of microgrids," in 2006 IEEE Power Engineering Society General Meeting, 2006, p. 8 pp.

[60] A. G. Tsikalakis and N. D. Hatziargyriou, "Centralized control for optimizing microgrids operation," in 2011 IEEE Power and Energy Society General Meeting, 2011, pp. 1-8.

[61] F. Chiou, J. P. Gentle and T. R. McJunkin, "Dispatchable renewable energy model for microgrid power system," in 2016 IEEE Conference on Technologies for Sustainability (SusTech), 2016, pp. 195-199.

[62] F. Katiraei, R. Iravani, N. Hatziargyriou and A. Dimeas, "Microgrids management," IEEE Power and Energy Magazine, vol. 6, no. 3, pp. 5465, 2008.

[63] F. A. Pamuji and H. Miyauchi, "A new control design of maximum power point tracking by fuzzy logic controller for wind turbine connected to low voltage grid," in 2016 International Seminar on Intelligent Technology and Its Applications (ISITIA), 2016, pp. 369372.

[64] J. Hui and P. K. Jain, "Power management and control of a wind energy conversion system (WECS) with a fuzzy logic based maximum power point tracking (MPPT)," in IECON 2012 - 38th Annual Conference on IEEE Industrial Electronics Society, 2012, pp. 5966-5971.

[65] M. Motevasel and A. R. Seifi, "Expert energy management of a microgrid considering wind energy uncertainty," Energy Conversion and Management, vol. 83, pp. 58-72, 7// 2014.

[66] E. Tsioumas, N. Karakasis, N. Jabbour and C. Mademlis, "Energy management and power control strategy at the low wind speed region of a wind generation microgrid," in IECON 2016 - 42nd Annual Conference of the IEEE Industrial Electronics Society, 2016, pp. 40974102.

[67] J. Patiño, A. Márquez and J. Espinosa, "An economic MPC approach for a microgrid energy management system," in 2014 IEEE PES Transmission \& Distribution Conference and Exposition - Latin America (PES T\&D-LA), 2014, pp. 1-6.

[68] M. Yu, Y. Wang and Y. G. Li, "Energy management of wind turbinebased DC microgrid utilizing modified differential evolution algorithm," in International Conference on Renewable Power Generation (RPG 2015), 2015, pp. 1-6.

[69] H. Babazadeh, W. Gao, Z. Wu and Y. Li, "Optimal energy management of wind power generation system in islanded microgrid system," in 2013 North American Power Symposium (NAPS), 2013, pp. 1-5.

[70] E. H. Camm et al., "Characteristics of wind turbine generators for wind power plants," in 2009 IEEE Power \& Energy Society General Meeting, 2009, pp. 1-5.

[71] E. Muljadi, Y. C. Zhang, V. Gevorgian and D. Kosterev, "Understanding dynamic model validation of a wind turbine generator and a wind power plant," in 2016 IEEE Energy Conversion Congress and Exposition (ECCE), 2016, pp. 1-5.

[72] Y. Zou and J. He, "Comprehensive modeling, simulation and experimental validation of Permanent Magnet Synchronous generator wind power system," in 2016 IEEE/IAS 52nd Industrial and Commercial Power Systems Technical Conference (I\&CPS), 2016, pp. 1-9.

[73] R. I. Putri, M. Rifa'i, L. Jasa, A. Priyadi, P. Margo and H. P. Mauridhi, "Modeling and control of permanent magnet synchronous generator variable speed wind turbine," in 2016 International Conference on Smart Green Technology in Electrical and Information Systems (ICSGTEIS), 2016, pp. 16-20.

[74] M. Rahimi and H. Assari, "Addressing and assessing the issues related to connection of the wind turbine generators to the distribution grid," International Journal of Electrical Power \& Energy Systems, vol. 86, pp. 138-153, 3// 2017.

[75] P. Ledesma and J. Usaola, "Doubly fed induction generator model for transient stability analysis," IEEE Transactions on Energy Conversion, vol. 20, no. 2, pp. 388-397, 2005.

[76] L. Yazhou, A. Mullane, G. Lightbody and R. Yacamini, "Modeling of the wind turbine with a doubly fed induction generator for grid integration studies," IEEE Transactions on Energy Conversion, vol. 21, no. 1, pp. 257-264, 2006.

[77] L. Xu, L. Yao and C. Sasse, "Grid Integration of Large DFIG-Based Wind Farms Using VSC Transmission," IEEE Transactions on Power Systems, vol. 22, no. 3, pp. 976-984, 2007.

[78] G. N. Sava, M. Q. Duong, S. Leva, M. Mussetta, S. Costinas and N. Golovanov, "Coordination control of active crowbar for doubly fed induction generators," in 2014 International Symposium on Fundamentals of Electrical Engineering (ISFEE), 2014, pp. 1-5.

[79] J. Lopez, E. Gubia, E. Olea, J. Ruiz and L. Marroyo, "Ride Through of Wind Turbines With Doubly Fed Induction Generator Under Symmetrical Voltage Dips," IEEE Transactions on Industrial Electronics, vol. 56, no. 10, pp. 4246-4254, 2009.

[80] R. Li, X. Dawei, P. J. Tavner and Y. Shunchang, "Control of a doubly fed induction generator in a wind turbine during grid fault ride-through," in 2006 IEEE Power Engineering Society General Meeting, 2006, p. 1 pp.

[81] J. Yao, H. Li, Y. Liao and Z. Chen, "An Improved Control Strategy of Limiting the DC-Link Voltage Fluctuation for a Doubly Fed Induction Wind Generator," IEEE Transactions on Power Electronics, vol. 23, no. 3, pp. 1205-1213, 2008.

[82] D. Santos-Martin, S. Arnaltes and J. L. Rodriguez Amenedo, "Reactive power capability of doubly fed asynchronous generators," Electric Power Systems Research, vol. 78, no. 11, pp. 1837-1840, 11// 2008.

[83] M. Kayikci and J. V. Milanovic, "Reactive Power Control Strategies for DFIG-Based Plants," IEEE Transactions on Energy Conversion, vol. 22, no. 2, pp. 389-396, 2007.

[84] B. C. Rabelo, W. Hofmann, J. L. d. Silva, R. G. d. Oliveira and S. R. Silva, "Reactive Power Control Design in Doubly Fed Induction Generators for Wind Turbines," IEEE Transactions on Industrial Electronics, vol. 56, no. 10, pp. 4154-4162, 2009.

[85] Tabassum, M., Haldar, M.K. and Khan, D.F.S., 2016. Implementation and performance evaluation of advance metering infrastructure for Borneo-Wide Power Grid. Frontiers in Energy, pp.1-20.

[86] Nabipour-Afrouzi, H., Yii, S.H.W., Ahmad, J. and Tabassum, M., 2018, October. Comprehensive Review on Appropriate Sizing and Optimization Technique of Hybrid PV-Wind System. In 2018 IEEE PES Asia-Pacific Power and Energy Engineering Conference (APPEEC) (pp. 364-369). IEEE.

[87] Maaji, S.S., Khan, D.F.S., Tabassum, M. and Haldar, M.K., PRELIMINARY STUDIES ON A Proposed BORNEO-WIDE SMART GRID.

[88] Maaji, S.S., Khan, D.F.S., Haldar, M.K., Tabassum, M. and Karunakaran, P., 2013. Integration of solar and wind power to a borneowide power grid. International Journal of Environmental Science and Development, 4(6), p.681.

[89] L. T. Hong, J. Ahmed, H. Nabipour-Afrouzi and S. Kashem, "Designing a PSCAD based PV simulator for partial shading to validate future PV application planning," 2018 IEEE PES Asia-Pacific Power and Energy Engineering Conference (APPEEC), Kota Kinabalu, 2018, pp. 526-531, doi: 10.1109/APPEEC.2018.8566639.

[90] J. Ahmed, Z. Salam, Y. L. Then and S. Kashem, "A fast MPPT technique based on I-V curve characteristics under partial shading," TENCON 2017 - 2017 IEEE Region 10 Conference, Penang, 2017, pp. 1696-1701, doi: 10.1109/TENCON.2017.8228132.

[91] C. T. K. Kho, J. Ahmed, S. Kashem and Y. L. Then, "A comprehensive review on PV configurations to maximize power under partial shading," TENCON 2017 - 2017 IEEE Region 10 Conference, Penang, 2017, pp. 763-768, doi: 10.1109/TENCON.2017.8227962.

[92] Chowdhury, M.A. and Kashem, S.B.A., 2018. Hळ loop-shaping controller design for a grid-connected single-phase photovoltaic system. International Journal of Sustainable Engineering, pp.1-9.

[93] Kashem, S.B.A., Sheikh, M.I.B., Ahmed, J. and Tabassum, M., 2018, April. Gravity and buoyancy powered clean water pipe generator. In 2018 IEEE 12th International Conference on Compatibility, Power Electronics and Power Engineering (CPE-POWERENG 2018) (pp. 1-5). IEEE.

[94] Mubarak, H. and Kashem, S.B.A., 2016. Comparison of different energy saving lights using solar panel. Frontiers in Energy, 10(4), pp.466-472. 
[95] M. B. M. Siddique, S. B. A. Kashem, K. Mathew "Home and Water Heating Using Biofuels" Proceedings of International Conference on Recent Innovations in Engineering and Technology, 2017.

[96] F. Tay, S. B. A. Kashem, "Automated Miniature Greenhouse", Advanced Science Letters 23.6 (2017): 5309-5313.

[97] Safe, A.A., Kashem, S., Moniruzzaman, M. and Islam, M.T., 2014, October. Design, fabrication \& analysis of twisted blade vertical axis wind turbine (VAWT) and a simple alternator for VAWT. In Strategic Technology (IFOST), 2014 9th International Forum on (pp. 304-308). IEEE.

[98] Mujahid Tabassum, S. B. A. Kashem, Kuruvilla Mathew, "Distributed energy generation - is it the way of the future?”, Proceedings of the 1st Springer International Conference on Emerging Trends and Advances in Electrical Engineering and Renewable Energy, 2016.

[99] Sheikh, M. Ismail Bilal, S. B. A. Kashem and Tanveer Choudhury. "Enhancing solar power generation using gravity and fresh water pipe." Proceedings of IEEE Xplore 2017, IEEE International Conference on Mechatronics, pp. 266-271, 2017.

[100]Tabassum, M., Kashem, S. B. A. and Siddique, M.B.M., Feasibility of using Photovoltaic (PV) technology to generate solar energy in Sarawak. In Computer and Drone Applications (IConDA), 2017 International Conference on (pp. 11-16). IEEE 2017, November.

[101]Siddique, M.B.M., Kashem, S.B.A. and Iqbal, A., Biofuels in Malaysian perspective: Debates and benefits. In Compatibility, Power Electronics and Power Engineering (CPE-POWERENG), 2018 IEEE 12th International Conference on (pp. 1-6). IEEE. April, 2018.
[102]Nushrat Shabrin, S. B. A. Kashem, et al., "Investment and Construction Cost Analysis on Net-Zero Energy Building Technology", International Journal of Mechanical and Production Engineering, ISSN: 2320-2092, Volume- 5, Issue-4,2017

[103]Nushrat Shabrin, S. B. A. Kashem, "A Comprehensive Cost Benefit Analysis of Green Building”, International Journal of Advances in Mechanical and Civil Engineering (IJAMCE), Volume 4 Issue 2, June 2017, ISSN: 2394-2827.

[104]Saad Bin Abul Kashem, Muhammad E. H. Chowdhury, Mujahid Tabassum, Majid E. Molla, Azad Ashraf, Amith Khandakar, "A Comprehensive Study on Biomass Power Plant and Comparison Between Sugarcane and Palm Oil Waste”, International Journal of Innovation in Computational Science and Engineering, Volume1 Issue 1, page 26-32, May 2020, ISSN: 2708-3128.

[105]Saad Bin Abul Kashem, Muhammad E. H. Chowdhury, Mujahid Tabassum, Majid E. Molla, Azad Ashraf, Jubaer Ahmed, "Feasibility Study of Solar Power System in Residential Area”, International Journal of Innovation in Computational Science and Engineering, Volume1 Issue 1, page 10-17, May 2020, ISSN: 2708-3128.

[106]Kashem, S.B.A., Sheikh, M.I.B., Ahmed, J. and Tabassum, M., 2018, April. Gravity and buoyancy powered clean water pipe generator. In 2018 IEEE 12th International Conference on Compatibility, Power Electronics and Power Engineering (CPE-POWERENG 2018) (pp. 1-5). IEEE. 